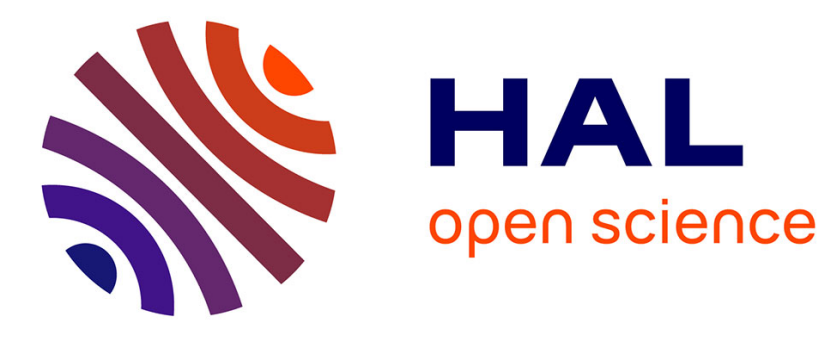

\title{
The molecular mechanisms of reaction wood induction
}

\author{
Kurt Fagerstedt, Kévin K. Tocquard, David Lopez, Mélanie Decourteix, \\ Bernard Thibaut, Jean-Louis J.-L. Julien, Philippe Label, Nathalie \\ Fournier-Leblanc, Patricia Roeckel-Drevet
}

\section{- To cite this version:}

Kurt Fagerstedt, Kévin K. Tocquard, David Lopez, Mélanie Decourteix, Bernard Thibaut, et al.. The molecular mechanisms of reaction wood induction. Barry Gardiner, John Barnett, Pekka Saranpää, Joseph Gril. The biology of reaction wood, Springer, pp.107-138, 2014, 978-3-642-10813-6. hal01135267

\section{HAL Id: hal-01135267 \\ https://hal.science/hal-01135267}

Submitted on 26 May 2016

HAL is a multi-disciplinary open access archive for the deposit and dissemination of scientific research documents, whether they are published or not. The documents may come from teaching and research institutions in France or abroad, or from public or private research centers.
L'archive ouverte pluridisciplinaire HAL, est destinée au dépôt et à la diffusion de documents scientifiques de niveau recherche, publiés ou non, émanant des établissements d'enseignement et de recherche français ou étrangers, des laboratoires publics ou privés. 


\title{
Chapter 4 \\ The Molecular Mechanisms of Reaction Wood Induction
}

\author{
Kurt Fagerstedt, Kévin Tocquard, David Lopez, Mélanie Decourteix, \\ Bernard Thibaut, Jean-Louis Julien, Philippe Label, Nathalie Leblanc- \\ Fournier, and Patricia Roeckel-Drevet
}

\subsection{Introduction}

Reaction wood (RW) develops in stems and branches in response to the perception 9 of endogeneous and environmental stimuli caused by a change in the natural 10 position. As a result the stem or branch bends back towards its original position. 11 It is generally stated that in most cases, in gymnosperms RW is formed on the lower 12 side of branches and bent stems and is called compression wood (CW). In angio- 13 sperms it is formed on the upper side of branches and bent stems and is called 14 tension wood (TW). Wood formed on the other side of branches and bent stems is 15 called opposite wood (OW). 16

It was commonly believed until the end of the 1980 s that RW was induced by the 17 stress state of the new wood layer at cambium vicinity. The bottom of a branch 18 should be in compression thus promoting CW in gymnosperms, the top being in 19 tension should promote TW in angiosperms. For experimentation the challenge was 20 to submit the external layer of a living stem to high tensile or compressive axial 21 stress without any other signal such as gravity or light, and without too big a 22

\author{
K. Fagerstedt $(\bowtie)$ \\ Division of Plant Physiology, Department of Biosciences, University of Helsinki, 00014 \\ Helsinki, Finland \\ e-mail: kurt.fagerstedt@helsinki.fi \\ K. Tocquard • D. Lopez • M. Decourteix • J.-L. Julien • P. Label • N. Leblanc-Fournier • \\ P. Roeckel-Drevet \\ Clermont Université - Université Blaise Pascal, INRA, UMR PIAF, BP 10448, 63000 \\ Clermont-Ferrand, France \\ B. Thibaut \\ Laboratoire de Mécanique et Génie Civil (LMGC), CNRS, Université Montpellier 2, \\ Place E. Bataillon, cc 048, 34095 Montpellier cedex 5, France
}


physiological stress due to the mechanical loading. Fournier et al. (1994) showed that the cross section grows while it is loaded. For each material point, the superposition of stress and strain begins from the time the material is differentiated. That comes from the obvious assumption that "a tissue cannot be loaded before it exists". The main consequence is that the new wood layer does not contribute at all to support the load of the existing trunk or branch and the resulting support stress should be zero at the stem periphery. A change of paradigm therefore had to be made: it is not the stress that induces RW formation but the RW formation that produces different stress levels (in tension or compression) in the new wood layer.

Very often, successive growth events are used by trees "to solve" some mechanical problem, in addition to building of the prescribed structure, in order to restore the posture of an inclined tree (Thibaut et al. 2001; Moulia et al. 2006), to search for the light, to change the tree architecture after death of a major axis, and so on. RW is a solution for a drastic and sudden change in the existing wooden structure of the tree. It is commonly used by all trees, particularly in the juvenile stage. RW is created very locally in answer to a global mechanical problem for the tree by creating a step change in the pre-stressing state of the new layer. According to modelling simulations, the curving efficiency of asymmetrical stressing of the axis using RW is nearly five times higher than the best solution using normal wood asymmetry alone (Almeras and Fournier 2009).

Solving the mechanical problems of a tree through growth is possible because of the flexibility in growth of the meristematic tissues in the length or ramification (primary growth) and the diameter (secondary growth) of each axis (trunks and branches). This structure needs to be mechanically sound and able to respond to most hazards faced by the tree. In the tree, each elementary growth event has to be precisely managed: action or dormancy, rapid or slow cell division, cell differentiation and cell wall formation. And each of these events has mechanical consequences. In addition, the new growth events that involve primary and/or secondary growth seem to be coordinated at the whole tree level. RW originates from cambial activity (secondary meristem), which adjusts the number of cell division to modify the axis diameter and in particular its second moment of area, as well as the proportion of fibres and the cell wall thickness to modify the density and the mechanical properties of the new layer. Through cambial activity the microfibril angle (MFA) in the S2 layer of the cell wall is also adjusted to modify the axis flexibility both by changing the modulus of elasticity for a given tissue density and the maximum allowed strain before damage (more flexibility appears to be an adaptation to wind); this may also modify the pre-stressing state of the new wooden layer. Last but not least, cambial activity adjusts the chemistry of cell wall components to modify the pre-stressing state of the new wooden layer; this may be done in conjunction with the adjustment of MFA (these changes are discussed further in Chaps. 2, 3, 5 and 6).

Hence, the following questions are raised concerning the induction of RW through modulation of cambial activity. What are the different external or internal signals related to secondary growth in order to solve different mechanical requirements? Where are the perception sites for the new mechanical requirements for the 
tree? Could a signal get to particular cells in the cambium in order to manage new 68 growth? If such a signal exists from the perceptive cells to the cambium, what about 69 the conversion of the perception into messages transmitted to the secondary mer- 70 istem? What is the process of "regulation"? How are these messages transcribed in 71 the making of RW? Also most of the questions raised for RW formation could also 72 be addressed to the regulation of primary growth since both primary and secondary 73 growth must be coordinated at the whole tree level.

In this chapter, after reviewing different kinds of signals (gravity, light, mechan- 75 ical strain) that can induce a mechanical reaction causing RW formation, we will 76 focus on the molecular mechanisms that might be involved in the perception and 77 response to gravity and other mechanical stimuli. Since it is quite clear that the 78 signal perception gives way to synthesis of proteins guiding the production or 79 translocation of various plant hormones, we will review their implication in the 80 gravitropic or phototropic mechanical response inducing the making of RW. We 81 will also discuss the insights provided by global approaches such as transcriptomic, 82 proteomic and metabolomics, made possible by the sequencing and annotation of 83 the genome of trees such as poplar and eucalyptus. In particular, these global 84 approaches gave new information on genes involved in RW formation.

\subsection{Perception and Signal Transduction}

\subsubsection{Physical Parameters Inducing $R W$}

To maintain a branching architecture that is optimal for growth and reproduction, 88 plant stems continuously control their posture to counterbalance environmental 89 physical parameters such as gravity, wind and light, that shift their orientation 90 from the vertical (Moulia et al. 2006). In trees, this postural control has been mainly 91 studied in response to gravity (Du and Yamamoto 2007). In the primary growing 92 zone of stems, reorientation of woody plant organs involves local differential 93 elongation growth between opposite sides of the stem. In stem parts undergoing 94 radial growth, sectors of RW are produced that can be associated with eccentric 95 cambial growth. In angiosperm woody species, TW is often characterized by fewer 96 vessels and the formation of fibres with smaller diameter containing a gelatinous 97 layer inside the S2 layer of secondary cell walls where cellulose microfibrils are 98 aligned into a vertical orientation (Fig. 4.1, Mellerowicz et al. 2008; Chap. 3) with a 99 lower lignin content (Pilate et al. 2004). In conifers, CW is characterized by 100 tracheids with a thicker secondary cell wall than in normal wood, with higher lignin 101 content, intracellular spaces at cell corners, and a realignment of cellulose micro- 102 fibrils in the S2 layer orientation with respect to the axis of the stem (Timell 1986). 103 These differences in secondary cell wall biochemical composition and architecture 104 of RW generate internal growth stresses in the stem (Chap. 5), and because of its 105 

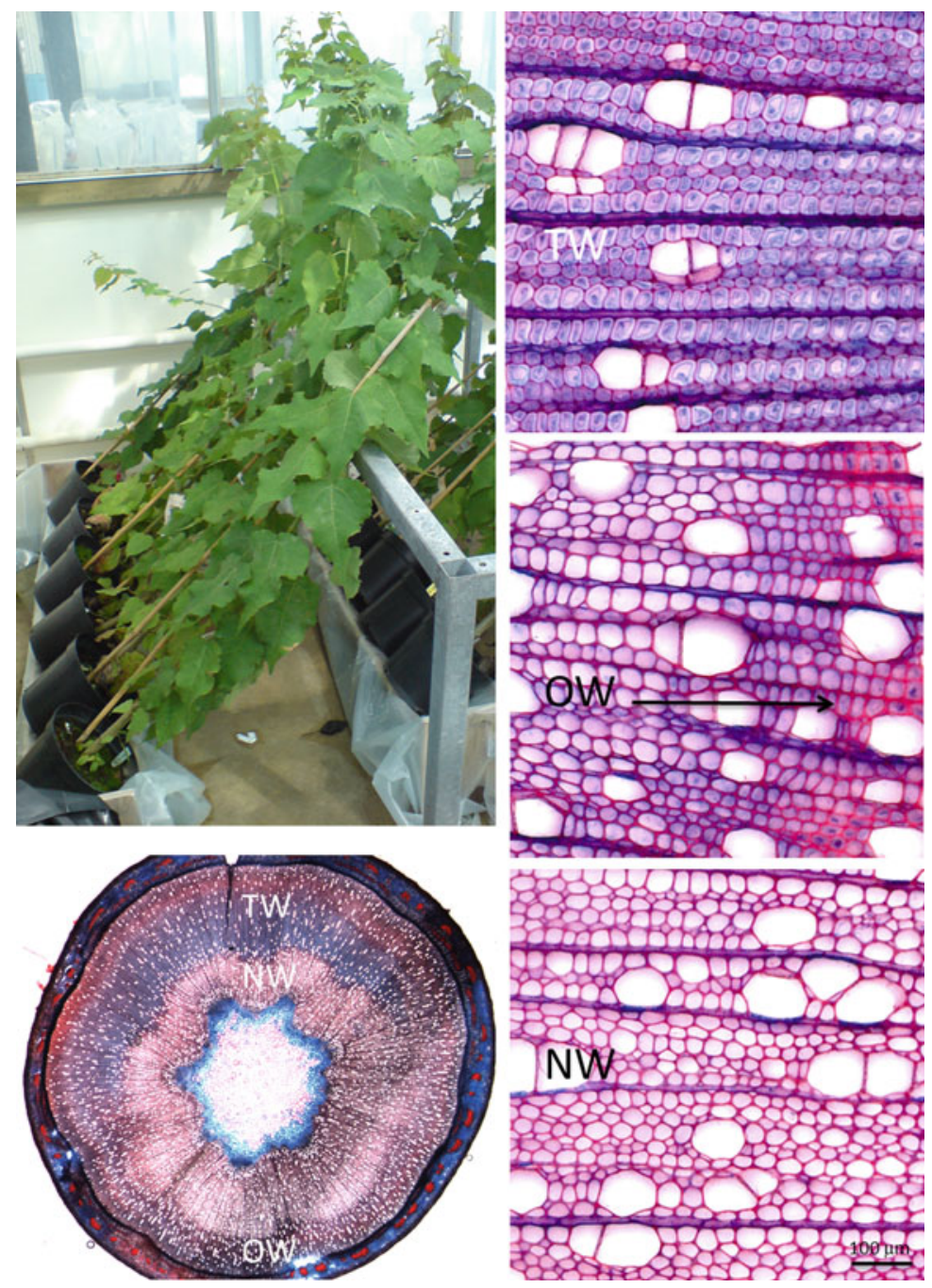

Fig. 4.1 Induction of TW by tilting of hybrid aspen trees (Populus tremula $\times$ tremuloides). After 17 days of tilting, a band of TW (TW) is seen on the upper side of the tilted stems. The mature normal wood $(\mathrm{NW})$ produced before tilting, and the opposite wood $(\mathrm{OW})$ produced at the lower side of the stems are shown at higher magnification on the right side of the figure. The sections were stained with safranin and alcian blue. Picture courtesy of Ewa Mellerowicz

unilateral formation in the stem, it induces a directional movement, bending the stem towards a favourable position.

As discussed recently by Felten and Sundberg (2013), many experiments were performed where branches or stems are tilted, bent into complicated shapes, grown on clinostats or centrifuges, to identify if a single stimulus is responsible for the induction of RW. For loop experiments on shoots or branches, the localization of 
RW suggested that its induction depends rather more on positional sensing (sensing 112 of the local angle of the growing organ relative to the gravitational field) than 113 sensing of mechanical stresses such as tensile or compressive stresses (Spurr and 114 Hyvärinen 1954).

However, RW formation is not only induced by gravitational stimulus. TW has 116 been reported to form in the vertical stems of rapidly growing poplar (Populus) 117 trees (Telewski 2006). RW was also observed in branches and stems contributing to 118 crowns reshaping after loss of apical dominance (Wilson and Archer 1977) and is 119 part of the mechanism allowing up-righting of apricot tree stems in response to 120 increased shoot and fruit load (Almeras et al. 2004). Plant exposure to wind spray or 121 to repeated stem bending to mimic the wind triggers (1) transitory inclination of the 122 stem, but with a duration of stem inclination much shorter than the presentation 123 time necessary to observe the induction of RW (Jourez and Avella-Shaw 2003) and 124 (2) mechanical signals such as stresses and strains. Exposition of poplar stems to 125 repeated transitory bendings produced a flexure wood with anatomical similarities 126 to TW (Pruyn 1997; Pruyn et al. 2000). In Abies fraseri, the morphology and 127 function of wood developed after daily flexures $(<20 \mathrm{~s})$ were more closely related 128 to CW than normal wood (Telewski 1989). CW was also detected in wind-treated 129 Pinus (Berthier and Stokes 2005). One of the best examples demonstrating that RW 130 is not exclusively induced in response to positional sensing came from analysis of 131 the kinematics of stem straightening (for review, see Moulia et al. 2006; Moulia and 132 Fournier 2009). The characterization of the spatio-temporal curvature field during 133 stem straightening allowed the recognition of a biphasic pattern: an initial phase of 134 spatially homogeneous up-curving due to gravitropic response and a second phase 135 of stem decurving that propagates basipetally to finally reach a steady state where 136 the curvature is concentrated to the base of the growth zone. In some plants, this 137 decurving phase occurred before the shoot apex had overshot the vertical, demon- 138 strating that this phenomenon was not due to the perception of the inclination angle, 139 and was called autotropism. This autotropic decurving has been observed in many 140 plants (Moulia et al. 2006). Studying this process in poplars (Populus nigra $\times 141$ Populus deltoides), Coutand et al. (2007) observed that no part of the trunk overshot 142 the vertical during stem straightening. Indeed, during the initial phase of 143 up-righting, arcs of RW were detected homogeneously all along the upper side of 144 the trunk, whereas a second sector of RW was produced on the initially lower side 145 in the most distal part of the trunk, contributing to this autotropic decurving. 146 Recently, Bastien et al. (2013) studied the gravitropism kinematics of different 147 organs from 11 angiosperms by time lapse photography, including both primary 148 elongation zones and zones of secondary growth in which active bending is 149 achieved through the production of TW. The biphasic pattern of tropic reactions 150 described above was found to be generic whatever the type of the organ, and it was 151 shown to lead to a steady state shape in which the apical part is straightened 152 whereas the curvature is more concentrated at the base of the stem. However, 153 inter- and intra-specific variability occurred in the steady states and in the tran- 154 sients: whereas some plant organs reached a steady state without overshooting the 155 vertical, others exhibited oscillations around the vertical axis. Bastien et al. (2013) 156 
also demonstrated that the minimal dynamic model cannot involve only gravisensing but the simultaneous sensing of the local curvature, referred by the authors as proprioception. When the organ is tilted and straight, gravisensitive control is dominant and the organ bends up actively. However as curvature increases, the inclination angle decreases and proprioceptive control takes over and autotropic counter-bending is produced starting in the apical parts of the organs, allowing it to straighten and align with the gravity vector. These data also suggest that the different shapes observed along the straightening response reflected a different ratio between graviceptive and proprioceptive sensitivities.

Another physical parameter that can influence reorientation of the stem by RW formation is light interception. Because of their co-occurrence under natural conditions gravi- and phototropism are intrinsically linked (Correll and Kiss 2002). Remarkably, phototropism sensing converges to common molecular actors with gravitropism and notably auxin transport and perception (Hohm et al. 2013). Typically, stems and stem-like organs have positive phototropism and negative gravitropism. Additive or synergetic effects were reported (Kern and Sack 1999) making the identification of their relative contribution and their possible interactions problematic. To address this issue, gravity effects were experimentally reduced or abolished (e.g. microgravity, space flight) while applying directional light source to induce phototropism (Millar and Kiss 2013). To date, it remains technically difficult to alleviate or reduce gravity effects on trees. The few possibilities offered to researchers consist in the manipulation of gravity orientation by tilting potted trees in combination with directional light modifications. Matsuzaki et al. (2006) report phototropism in trees submitted to different gravitational stimulations as observed on mountain slopes. Basal parts of the trees did not show bending in response to tropisms, which was limited to upper parts of stems. The authors suggested that reorientation could be achieved by asymmetric radial growth due to the formation of RW as is the case for gravitropism and further proposed trees inclination on slopes depends on phototropism. The same team later proved that the mechanism involved in phototropism required differential xylem production (Matsuzaki et al. 2007). In a recent study, Collet et al. (2011) studied long-term (4 years) phototropic response of Fagus sylvatica and Acer pseudoplatanus after canopy opening in natural conditions. Plants reacted by righting themselves towards the light source and this involved reorientation of the lignified parts of the stems through asymmetrical formation of RW. Herrera et al. (2010) noticed changes in the orientation of apical part of pine seedlings but not in the basal parts even after 22 days of light and gravi-stimulation. Although limited to primary growth, this work provided molecular data on the interaction of these two tropisms, scarce for tree models. Interestingly, photo- and gravitropic responses of potato plants were different depending on the time of the day suggesting they were also regulated by an endogenous circadian clock to some extent (Vinterhalter et al. 2012). Such complexity, far from being completely understood in herbaceous plants, still needs to be established in trees where secondary growth in reaction to phototropism and gravitropism is still a matter of exploration. 
All these data converge on the induction of RW during plant postural control. 202 Clearly the triggering of RW formation during tropic reaction not only is related to 203 the sensing of the inclination of the stem versus gravity but also involves curvature 204 sensing. TW has been shown to systematically be formed on the lower side of the 205 branch when autotropism dominates gravitropism, allowing for curvature compen- 206 sation (Coutand et al. 2007). Similar shifts in the location of RW along the tropic 207 motion have also been described for CW in conifers (Sierra de Grado et al. 2008). 208 But, how these diverse physical parameters (gravity, local curvature, light) are 209 perceived by plant cells in order to induce RW remains unclear. Are all these 210 physical parameters perceived by a common sensing mechanism or is there any 211 crosstalk at a later stage during the signaling pathway?

\subsubsection{Molecular Mechanisms Involved in the Perception of Mechanical Stimulation Leading to $R W$ Formation}

In case of a gravitational stimulus, the resulting physical forces can deform or move 215 objects of specific mass inside the cell. Two hypotheses are currently favoured: 216 (1) the amyloplast-sedimentation in specialized cells named statocytes and the 217 perception of the direction of this sedimentation and (2) the weight of the proto- 218 plasm itself triggering mechanical deformation of subcellular structures such as 219 membrane, cytoskeleton elements and cell wall (Baluška and Volkmann 2011).

The role of starch-filled amyloplast sedimentation during graviperception is well 221 documented in Arabidopsis (Morita 2010). In young shoots, statocytes are localized 222 in the endodermis layer surrounding vascular tissues. These cells are highly vacu- 223 olated and equipped with prominent F-actin bundlets (Morita et al. 2002). The 224 studies of different mutants affected either in starch formation $(\mathrm{pgm})$ or in intra- 225 cellular components such as the vacuolar membrane (VM) or actin microfilaments 226 (AFs) that both modify cytoplasm viscosity and activity showed that amyloplast 227 dynamics are important during shoot gravisensing (for review, Hashiguchi 228 et al. 2013). Recently, by using a centrifuge microscope to analyse gravitropic 229 mutants in Arabidopsis, Toyota et al. (2013) confirmed the importance of amylo- 230 plast movement perception during shoot gravisensing. In woody species, amylo- 231 plast localization in endoderm cells has been observed (Nakamura 2003) in the 232 young shoots of Japanese flowering cherry tree (Prunus spachiana) and in young 233 poplars (Populus tremula $\times$ alba) (Fig. 4.2a-d). However, a link between amylo- 234 plasts sedimentation and RW formation has not yet been demonstrated. Moreover, 235 the endoderm is disrupted by secondary growth. In cross sections of older poplar 236 stem, lugol-stained starch grains are observed in whole bark tissue as well as in the 237 wood rays (Fig. 4.2e). 238

The cellular mechanism underlying curvature proprioception is unknown 239 (Bastien et al. 2013). The sensing of cell deformation (strain sensing) or more 240 precisely of the deformation of some cellular component is a good candidate 241 

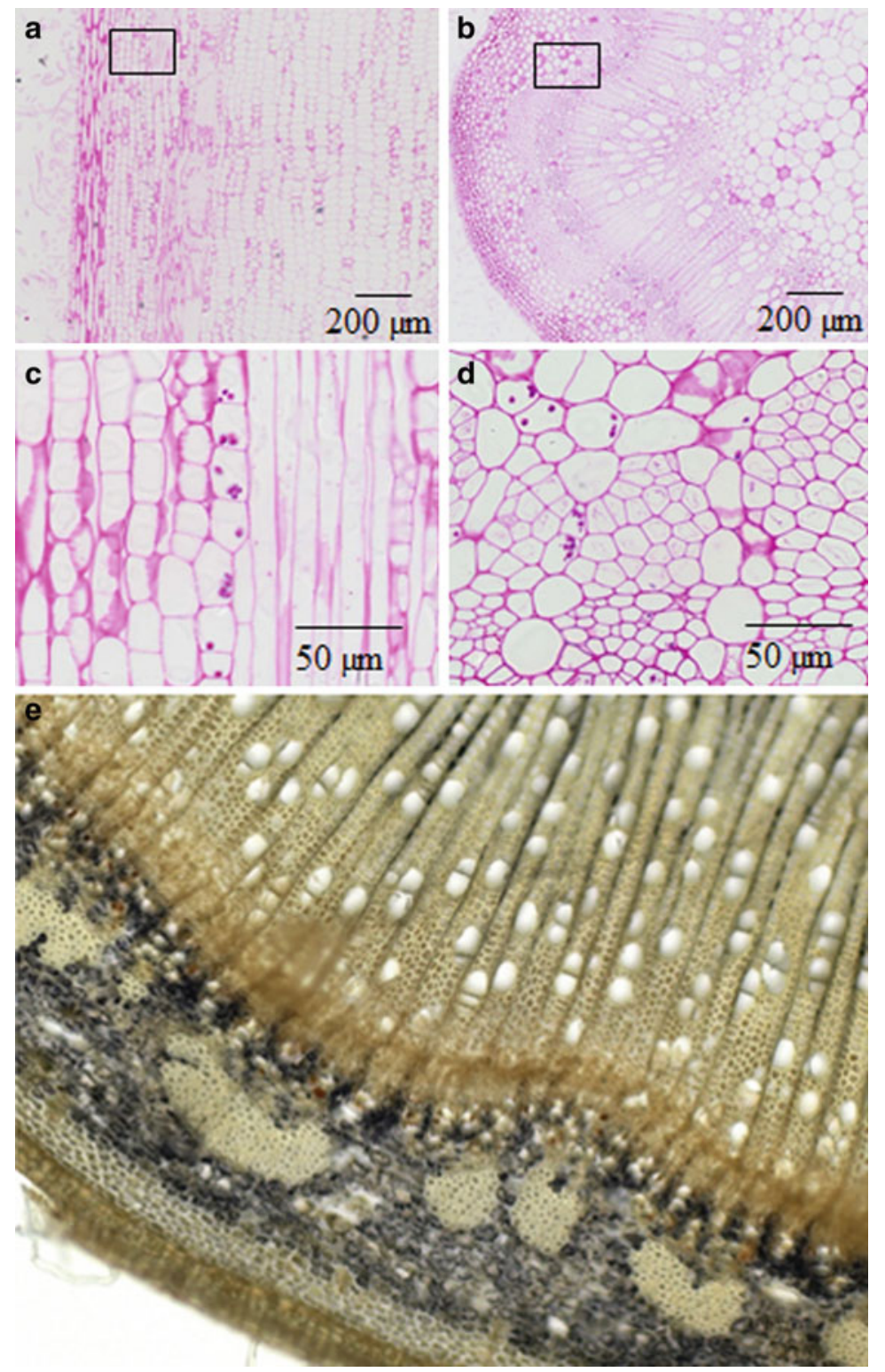

Fig. 4.2 Sections of poplar stems (Populus tremula $\times$ alba). Photographs $(\mathbf{a}-\mathbf{d})$ represent sections from the fourth bottom internode of a young plant with 20 developed internodes. Longitudinal sections (a, c) or transversal sections (b, d) were stained using Periodic acid/Schiff (PAS) reaction to detect starch and polysaccharides. Photographs (c) and (d) are, respectively, enlarged views of the photographs (a) and (b) (black rectangle area). Photographs courtesy of Wassim Azri. (e) This picture represents a cross section of a poplar stem, $40 \mathrm{~cm}$ under the apex. The tree height was $2.35 \mathrm{~m}$ and the diameter of the section is $5.3 \mathrm{~mm}$. The freehand cut was stained by lugol. Photographs courtesy of Kevin Tocquard 
(Wilson and Archer 1977; Bastien et al. 2013). Moreover the perception of the 242 deformation of cellular components is suggested also through amyloplast sedimen- 243 tation, in the gravitational pressure model (Baluška and Volkmann 2011), and 244 through wind sensing (Moulia et al. 2011). A few molecular candidates have 245 been identified as mechanoperceptors of this deformation. In trees, these are only 246 putative. Results obtained from the herbaceous model plant Arabidopsis thaliana 247 suggest molecular candidates at the CPMCW (cytoskeleton-plasma membrane- 248 cell wall) continuum. They would be able to sense the mechanical signal from the 249 plant cell wall and convert it into a molecular signal in the cell (Baluška et al. 2003; 250 Telewski 2006).

The first molecular candidates are mechanosensitive (MS) ion channels. MS ion 252 channels are membrane proteins that allow the transit of ions through cellular 253 membranes. They open either directly by the force applied on the membrane or 254 indirectly through links between the channels and/or both the cytoskeleton and cell 255 wall components (Haswell et al. 2011). To date the involvement of MS ion channels 256 in the perception of mechanical signals has yet to be clearly established. Neverthe- 257 less, several pieces of evidence show that ionic changes occurred after mechanical 258 signals (Haley et al. 1995). In plants, MS ion channels $\left(\mathrm{Cl}^{-}, \mathrm{K}^{+}\right.$and $\left.\mathrm{Ca}^{2+}\right)$ have 259 been identified at plasma membranes using patch-clamp electrophysiology 260 (Cosgrove and Hedrich 1991; Ding and Pickard 1993; Haswell et al. 2008). Cur- 261 rently three main groups of MS ion channels have been described in plants. First, 262 the mechanosensitive channel of the small conductance (MscS) family from 263 Escherichia coli which releases osmolytes from the cell (Booth and Blount 2012) 264 has ten homologues (MSL1-10) in the A. thaliana genome (Pivetti et al. 2003). 265 $\mathrm{MscS}$ homologues may release osmolytes in response to membrane tension and 266 may be modulated by additional signals (Monshausen and Haswell 2013). The 267 second Mid1-complementing activity (MCA) family is structurally unique to the 268 plant kingdom. The MCA proteins are located in the plasma membrane and 269 promote calcium influx upon mechanical stimulation (Nakagawa et al. 2007). 270 Finally, the Piezo proteins are a class of MS cation channels which respond to 271 mechanical stimuli (Coste et al. 2012; Kim et al. 2012). In Arabidopsis, there is a 272 single Piezo protein (Coste et al. 2010; Kurusu et al. 2013; Monshausen and 273 Haswell 2013) but it has yet to be characterized. $\quad 274$

Other molecular candidates are receptor-like kinases proteins (RLKs) that are a 275 family of proteins with an extracellular domain, a single transmembrane region and 276 an intracellular cytoplasmic kinase (Shiu and Bleecker 2001). Among RLKs, wall- 277 associated kinases (WAKs) are the most well-studied potential cell wall status 278 receptors (He et al. 1999; Verica and He 2002). They have a particular interest 279 because WAKs extracellular domains are able to bind to the cell wall 280 (He et al. 1996). Notably, Wagner and Kohorn (2001) showed that AtWAKs 281 covalently bind the cell wall pectins, in a calcium-induced conformation (Decreux 282 and Messiaen 2005). Moreover, a reduction of WAK expression inhibited cell 283 elongation and altered morphology (Lally et al. 2001; Wagner and Kohorn 2001), 284 indicating an activity in growth control. Therefore, WAKs are interesting candi- 285 dates as sensors of cell wall integrity. Another candidate among RLKs for sensing 286 
the cell wall integrity is the Catharanthus roseus RLK1-like subfamily (CrRLK1L). The 17 members present an extracellular malectin-like domain (Lindner et al. 2012). Malectin proteins bind to glycoproteins in animal endoplasmic reticulum (Qin et al. 2012). The hypothesis that the malectin-like domain of CrRLK1L proteins binds cell wall polysaccharides or glycoproteins in plants has been proposed (Monshausen and Haswell 2013). In this subfamily THESEUS1 (THE1), a particular member with a plasma membrane location, could be a candidate for cell wall integrity sensing in Arabidopsis. THE1 was identified at a suppressor screen of cellulose-deficient mutant cesA6 (Hématy et al. 2007). The thel mutant partially restored the hypocotyl elongation of the cesA6. However, mutations or over-expression of the THE1 gene did not exhibit any effects in Arabidopsis. Consequently, THE1 was therefore proposed as a sensor of the cell wall status and modulator of cell elongation during perturbed cellulose synthesis.

Members of ArabinoGalactan proteins (AGPs) bind pectins and are also hypothesized to be cell wall integrity sensors. Indeed, AGPs are highly glycosylated proteins located in the cell wall (for more detail, see Chap. 3). Some AGPs bind cell wall pectin (Serpe and Nothnagel 1995) and could be attached to the plasma membrane via GPI anchors which would mediate intracellular signaling (Humphrey et al. 2007).

\subsubsection{Mechanical Signal Transduction: Secondary Messengers}

Regarding secondary messengers, few data are available in trees and almost lacking in the context of gravitropic stimulation and/or stem bending. However, herbaceous plant model data can be a starting point for future studies on tree models. According to Toyota and Gilroy (2013), calcium is an important and ubiquitous cell secondary messenger. Its specific role as a secondary effector in MS signaling has been extensively investigated in Arabidopsis and Nicotiana (Knight et al. 1991, 1992; Haley et al. 1995; Plieth and Trewavas 2002; Toyota et al. 2008). Gravity stimulation of Arabidopsis seedlings indicated a cytosolic $\mathrm{Ca}^{2+}$ concentration $\left[\mathrm{Ca}^{2+}\right]_{\mathrm{cyt}}$ increase with a first sharp increase followed by another less intense but longer signal (Plieth and Trewavas 2002). Wind also induced $\left[\mathrm{Ca}^{2+}\right]_{\mathrm{cyt}}$ increase in Nicotiana and Arabidopsis seedlings (Knight et al. 1992; Haley et al. 1995; Plieth and Trewavas 2002). Experiments conducted on trees support the involvement of $\mathrm{Ca}^{2+}$ in RW formation. By using a $\mathrm{Ca}^{2+}$ chelator (EGTA) or a calcium channel inhibitor $\left(\mathrm{LaCl}_{3}\right)$ which allowed modification of $\mathrm{Ca}^{2+}$ availability, $\mathrm{CW}$ formation was inhibited in Taxodium distichum gravistimulated stems (Du and Yamamoto 2003). The involvement of calcium in TW induction has also been suggested by indirect data obtained from several global approaches (see Sect. 4.4) notably through regulation of protein accumulation such as calreticulin, $\mathrm{a} \mathrm{Ca}^{2+}$ storage 
protein (Azri et al. 2009). The overall results suggested $\mathrm{Ca}^{2+}$ ion as a second 326 messenger in the early stages of mechanical signal transduction.

Other secondary messengers have been identified as important after mechanical/ 328 gravitational stimulation. Azri et al. (2009) suggested the involvement of reactive 329 oxygen species (ROS) in poplar TW formation induced through the accumulation 330 of glutathione-dehydroascorbate reductase (GSH-DHAR), glutathione 331 S-transferase (GST) and thioredoxin $h$ (Thr $h$ ) proteins. Azri et al. (2013) further 332 showed an induction of the $T h r h$ gene in response to gravitropic stimulus. With an 333 immuno-chemistry approach, they co-located Thr $h$ proteins with amyloplasts in 334 stem endoderm cells, thus providing a coherent framework for graviperception. 335 More evidence from herbaceous models demonstrates that an interplay of ROS and 336 $\mathrm{Ca}^{2+}$ could mediate mechanosensing: ROS can stimulate $\left[\mathrm{Ca}^{2+}\right]_{\mathrm{cyt}}$, and an increase 337 of $\left[\mathrm{Ca}^{2+}\right]_{\text {cyt }}$ can also lead to a ROS production via NADPH oxidase (Mori and 338 Schroeder 2004).

Molecular candidates to convert the transient ionic $\mathrm{Ca}^{2+}$ signal to long-term 340 biochemical signal are mainly calmodulins $(\mathrm{CaM})$ and $\mathrm{Ca}^{2+}$-dependent protein 341 kinases (CDPK). Calmodulins are $\mathrm{Ca}^{2+}$-dependent regulation proteins linking cal- 342 cium to MS. CDPK are cytosolic proteins with a kinase domain, an autoinhibitory 343 domain, and a calmodulin-like domain that bind calcium ions (Hrabak et al. 2003). 344 In poplar, the expression of calmodulin encoding genes is up-regulated as soon as 345 10 min after a transient stem bending (Martin et al. 2009). Although very likely, a 346 role for these proteins in the $\mathrm{Ca} \quad$ signaling after mechanical stimulation still needs 347 to be demonstrated. 348

Phosphatidylinositol signaling is another part of the gravitropism sensing net- 349 work (Strohm et al. 2012). Membrane phospholipid Phosphatidylinositol 350 4,5-bisphosphate (PIP2) releases inositol 1,4,5 triphosphate (IP3 or InsP3) after 351 phospholipase C (PLC) hydrolysis. InsP3 is accumulated during gravitropic 352 response which later is repressed through PLC inhibition (Perera et al. 2001). 353 InsP3, like $\mathrm{Ca}^{2+}$, is a second messenger suggested as triggering intracellular 354 calcium flow from vacuole (Allen et al. 1995).

Taken together, these results indicate that complex and interactive signaling 356 pathways are involved after mechanical/gravitational stimulation. To date, no study 357 has yet addressed these mechanisms in tree stems. Numerous questions remain to be 358 resolved to understand the induction of RW. Why RW is produced in only one side 359 of the stems, whereas the physical parameters triggering RW production are 360 potentially perceived on both sides of the stem. Are the putative receptors uni- 361 formly localized in cells? Furthermore, if the endodermis cells are considered as 362 sensitive cells, how is the inductive signal transmitted to cambium cells or devel- 363 oping xylem cells to modify the secondary wall composition and architecture? 364 What cells act as gravisensor in older stems? How and where does crosstalk 365 between gravisensing and proprioception occur? 


\subsection{Signal Transmission to Reaction Wood-Forming Cells}

\subsubsection{Hormone Action and Reaction Wood}

The anatomical and biochemical features of RW have been the subject of extensive studies, which are described and reviewed in Chaps. 2 and 3. However the physiological and molecular signals inducing the formation of RW remain poorly described. Several plant hormones have been implicated in the regulation of cambial cell proliferation activity and in wood cell differentiation (for review, see Elo et al. 2009; Nieminen et al. 2012; Ursache et al. 2013). Until recently, their role in RW formation was studied through the application of exogenous compounds, the hormones themselves, their antagonists or transport/perception inhibitors. These experiments proved to be very informative as a first step towards deciphering whether hormones have the potential to induce RW formation. However, the possibility to genetically transform poplar and the use of high throughput molecular technics are, and will be continue to be, of great help in confirming and completing these observations.

\subsubsection{Auxin}

The application of auxin antagonists or transport inhibitors on both gymnosperm and angiosperm tree stems led to the assumption that auxin plays a role in RW formation. Increased amounts of auxin could induce CW formation in gymnosperms while a deficiency in auxin was required to form TW in angiosperm (for review, see Du and Yamamoto 2007; Felten and Sundberg 2013). However, such experiments do not prove the function of auxin under natural conditions because of the risk of uncontrolled modification of auxin homeostasis. To be validated, they need a better documentation of in planta auxin concentrations/amounts. Reports on the relationship between endogenous auxin levels and the formation of CW or TW are scarce and sometimes contradictory. For example, while Wilson et al. (1989) did not find a clear and conclusive correlation between the occurrence of $\mathrm{CW}$ and auxin concentrations, Funada et al. (1990) working on Cryptomeria japonica and Du et al. (2004) working on Metasequoia glyptostroboides found a higher amount of endogenous IAA (indole-3-acetic acid) in the cambial region producing CW. More recently, Hellgren et al. (2004) conducted a kinetic survey of endogenous IAA distribution across the cambial region of Aspen ( $P$. tremula) and Scots pine (Pinus sylvestris) trees after bent-stem gravistimulation. These experiments showed that RW could be formed even when the pattern of IAA distribution in the cambial region is unmodified. The authors concluded that modulation of the auxin concentration gradient across the cambial zone might not be the signal that maintains the cells in an RW developmental state.

Data found in the literature are contradictory and were obtained on different species with different techniques and at different time points after stimulation. It is 
therefore difficult to give a clear model of auxin role in RW formation. However, an 406 involvement of auxin in the early steps of the induction process has not yet been 407 ruled out. Actually, several reports showed that auxin signaling is responsive to 408 gravistimulation. After $6 \mathrm{~h}$ of stem bending, the expression of two AUX/IAA genes 409 in poplar (P. tremula $\times$ tremuloides) (Moyle et al. 2002) and one in Eucalyptus 410 (Paux et al. 2005) was altered in TW compared to normal wood in unbent trees. In 411 yellow poplar (Liriodendron tulipifera), a species that does not produce a typical 412 G-layer, the expression of ARFs and AUX/IAA genes as well as other auxin-related 413 genes is modified in TW compared to OW (Jin et al 2011). Similar results were also 414 obtained in poplar $(P$. tremula $\times$ tremuloides $)$ after 3 weeks of TW induction by 415 leaning the stem (Andersson-Gunnerås et al. 2006). 416

High throughput approaches have already helped in improving our knowledge of 417 auxin function in TW formation. Coupling these with functional genomic 418 approaches could help to gain a better understanding of the role of auxin in TW 419 formation.

\subsubsection{Ethylene}

The gaseous hormone ethylene has long been known to be produced in response to 422 diverse stresses including mechanical solicitations (for review, see Braam 2005; 423 Telewski 2006; Du and Yamamoto 2007) such as bending and tilting. These 424 stresses usually stimulated wood production by increasing cambial activity and 425 sometimes led to the production of RW. Like auxin, ethylene involvement in RW 426 formation was first investigated by measuring ethylene or its precursor (ACC: 427 1-aminocyclopropane-1-carboxylic acid), and by using application experiments. 428 For example, in the vascular cambium of Pinus contorta Dougl. ssp. latifolia 429 branches, endogenous ACC was detected in association with CW differentiation, 430 but not with OW (Savidge et al. 1983). Applications of ethrel, an ethylene releasing 431 compound, stimulated wood production and were able to modify anatomical fea- 432 tures of xylem in gymnosperm and angiosperm trees (Du and Yamamoto 2007). In 433 angiosperm, although some of these features, like fewer and smaller vessels, can be 434 reminiscent of TW characteristics (Little and Savidge 1987; Du and Yamamoto 435 2007; Love et al. 2009), it has to be noted that there is no report of G-layer induction 436 by ethylene treatments.

Molecular approaches have helped to gain new insights about regulation of TW 438 formation by ethylene. In bent poplars ( $P$. tremula $\times$ tremuloides), a clear induc- 439 tion of PttACO1 (ACC oxidase the last enzyme in the ethylene biosynthesis 440 pathway) expression and relative activity were observed in the TW-forming tissues 441 (Andersson-Gunnerås et al. 2003). Therefore, PttACO1 may represent a major 442 control of ethylene asymmetric production during TW formation. In poplars leant 443 for 3 weeks, the expression of genes related to ethylene signaling was also modified 444 in TW compared to OW (Andersson-Gunnerås et al. 2006). In L. tulipifera, such 445 modifications were seen as soon as $6 \mathrm{~h}$ after bending of the stem (Jin et al. 2011). 446 Love et al. (2009) combined the use of ethylene-insensitive trees, ethylene- 447 
overproducing trees, and the application of the ethylene-perception inhibitor MCP (1-methylcyclopropene) to explore ethylene physiological function in gravistimulated poplars. They showed that ethylene could be responsible for the stimulation of cambial cell divisions on the upper TW-forming side of leaning stems. In 2013, Vahala et al. identified 170 gene models encoding ERFs (ethylene response factors) in the Populus trichocarpa genome. Among these, 17 had a minimum of a twofold induction of expression in TW compared to normal wood. Over-expression of some of them in poplar resulted in anatomical or wall chemistry modifications that are reminiscent of TW features.

Ethylene and its signaling pathway seem therefore to control part of the molecular and physiological modifications underlying RW formation, especially the asymmetric increase in radial growth. However, it seems that the establishment of the full characteristics of RW involves ethylene in combination with yet unidentified other signaling factors (Love et al. 2009; Vahala et al. 2013; Felten and Sundberg 2013).

\subsubsection{Gibberellins}

Gibberellins (GAs) constitute another group of plant hormones known to promote secondary growth and xylem fibre length (Eriksson et al. 2000; Mauriat and Moritz 2009; Gou et al. 2011). Applications of exogenous GAs or GA inhibitors to tree stems can only provide indirect evidence for a role of GA in RW formation. In gymnosperms, the possibility of a role of GAs in CW formation has not yet been clearly demonstrated. However, experiments conducted on upright or tilted angiosperm trees helped to establish a correlation between GA and TW formation. For example, it has been shown that the application of GA to vertical stems of Fraxinus mandshurica, Quercus mongolica, Kalopanax pictus and Populus sieboldii induced the development of TW with typical G-fibres in the absence of gravistimulus (Funada et al. 2008). When tilted Acacia mangium seedlings were treated with GA their negative gravitropsim was stimulated. On the contrary, when they were treated with paclobutrazole or uniconazole-P, inhibitors of gibberellin biosynthesis, the gravistimulated upright movement of the acacia stems was inhibited and the formation of TW was suppressed (Nugroho et al. 2012, 2013).

No functional genomic experiment has yet proved that gibberellins could control $\mathrm{RW}$ formation. However, the use of a natural weeping mutant of $P$. spachiana brought some evidence for a role of GAs in TW formation. Exogenous application of GAs on branches of these Japanese cherry trees ( $P$. spachiana) stimulated cambial growth and promoted TW formation on the upper side of branches resulting in an upright movement (Nakamura et al. 1994; Baba et al. 1995; Yoshida et al. 1999).

Together these results indicate that GAs seem to be involved in RW formation. However, more direct supporting evidence and a better understanding of the involved signaling factors is still needed to make a clearer conclusion. 
As mentioned above, although sometimes quite indirect, an important amount of 489 data indicates a role for auxin, ethylene and gibberellins in RW formation. This 490 holds especially true for angiosperms since knowledge obtained on CW is less 491 advanced. On the contrary, no such relation has been identified for cytokinins, 492 abscissic acid or brassinosteroids. Most of the experiments designed to gain a better 493 understanding of the role of plant hormones in TW formation focused on a single 494 hormone, studied independently. It is, however, important to keep in mind that 495 many hormones have been shown to interact with each other in a synergistic or 496 inhibitory manner. For example, GA is known to stimulate polar auxin transport 497 (Björklund et al. 2007) and IAA to promote ethylene biosynthesis (Abeles 498 et al. 1992). Although the studies made so far have greatly improved our knowledge 499 of RW biology, the use of high throughput molecular technics combined with 500 functional genomics has started to, and should in the future, help to gain a deeper 501 understanding of the processes underlying RW development. Moreover, hormones 502 are currently mostly regarded as upstream primary responses to TW sensing (Felten 503 and Sundberg 2013), but studies on hormone distribution and transport are still too 504 scarce and contradictory to rule out the possibility of their involvement in the 505 transmission of the signal from the perceptive to the RW-forming cells.

\subsubsection{Other Candidates for Signal Transmission to Reaction Wood-Forming Cells}

miRNAs are small non-coding RNA molecules (about 21 nucleotides) which cleave 509 or degrade messenger RNA targets. In plants, they are involved in the regulation of 510 a large number of physiological processes (Jones-Rhodes et al. 2006) through the 511 targeting of cell metabolism, signal transduction and stress response mRNAs. 512 Different authors (Griffiths-Jones et al. 2008; Lu et al. 2005, 2008; Zhang 513 et al. 2010) have characterized mechanical stress-responsive miRNAs in 514 $P$. trichocarpa, especially miRNA that were differentially regulated by bending. 515 The predicted target genes encode transcription factors and proteins involved in 516 various cellular processes. For example, the function of the target of miR1446 is a 517 gibberellin response modulator-like protein and the target of miR160 is an auxin 518 responsive factor. Although a direct link between miRNAs and RW has never been 519 proven, the above-mentioned data indicate that these small molecules could be 520 good candidates to explore the molecular network controlling RW formation. To do 521 so, further genome-wide identification of miRNAs using a different experimental 522 design (inclination) is needed, as well as functional characterization of the identi- 523 fied miRNA and corresponding targets.

Recently, several authors reported intercellular signaling by miRNAs and 525 showed that some can move from one cell to another or over long distances (for 526 review, see Marín-González and Suárez-López 2012). Since signaling from the 527 cells that perceive the RW-generating stimuli to the RW-forming cells may require 528 
long distance regulation of gene expression, it is tempting to consider miRNAs as good candidates for the signal transmission from perceptive cells to RW-forming cells.

\subsection{Insights from Global Approaches}

Despite the economic impact of RW occurrence in industrial process and its importance from a tree developmental point of view, the molecular mechanisms involved in the perception and response to the gravitational stimulus have not been extensively studied. Furthermore, very few studies have addressed this question by global approaches, which require the genome of the studied tree species to be sequenced and annotated.

Investigating the induction of RW is also a very complex question RW is formed very locally in answer to a global mechanical problem for the tree. In addition most of the regulations used in RW formation (division rate, cell elongation, cell wall thickening, MFA setting) are also used for normal wood formation. Experimental setups have to take into account this point to specifically address the question of $\mathrm{RW}$ induction. Most of the studies on genes or proteins acting as regulators of RW making were done on inclining experiments. By inclining the whole tree system by an angle of around $30^{\circ}$ and letting it grow afterwards (see Chap. 5) a pure, longlasting RW formation is induced at the base of the stem (see Fig. 4.1). At inclination angles of this magnitude there is a strong perception of disequilibrium, secondary growth processes are very active and no new primary axillary growth is observed. This is in contrast to very inclined (nearly horizontal) trees, which use growth through axillary buds (i.e. primary growth) to create new vertical axes.

\subsubsection{Transcriptome Analysis}

Transcriptomics of RW is still in its infancy. Quite limited reports are available although studies have been conducted for about two decades. Regarding the vast majority of transcriptomics works on normal wood, the reader should refer to the most recent review of Zhong and Ye (2013). Early work addressed gene expression during RW formation through target genes approaches, leading progressively to recent transcriptome-wide overviews. Tools for deciphering gene involvement in the control of RW formation are becoming increasingly available and although most recent gene expression measurement tools, such as RNAseq, are still underused in this research field, hopefully this will change in the near future.

Most studies of angiosperm RW formation using transcriptomics have been conducted with poplar species and less frequently with Eucalyptus grandis, Eucalyptus globulus and Eucalyptus nitens. Other angiosperms species have been rarely studied with the exceptions of A. thaliana and the tulip tree (Liriodendron sp.). In 
gymnosperms, most studies have been conducted with Picea taeda although Pinus 566 pinaster, Pinus radiata, Picea abies, Picea glauca and Chamaecyparis obtusa have 567 also been examined. Target gene studies began in this research area with the 568 reporting of the involvement of 4-coumarate:coenzyme A ligase (4CL) during 569 CW formation (Zhang and Chiang 1997). Along with up-regulation of $4 C L$ tran- 570 scripts, the corresponding enzyme activity was also increased and its impact on 571 lignin composition was observed. Regulators of lignin biosynthesis have been 572 targeted as well, namely MYB factors in P. glauca (Bedon et al. 2007). 573

Meanwhile, transcriptome profiling started with the pioneering work showing 574 Pinus taeda transcripts down-regulated for genes involved in lignin biosynthesis 575 (Allona et al. 1998) and later in C. obtusa (Yamashita et al. 2008). At the same time, 576 a large diversity of responses was reported for carbohydrates enzymes, 577 i.e. xyloglucan endo-transglycosylase (XET), in CW using 1,097 ESTs in a 578 co-expression clustering study (Allona et al. 1998). AGPs were reported as 579 key-players through cDNAs encoding six novel so-called cell wall-associated pro- 580 teins in CW formation by the same approach (Zhang et al. 2000). These results were 581 further developed with a set of 2,400 ESTs from a cDNA microarray where 33 out 582 of 69 transcripts were differential in CW and related to monolignols biosynthesis 583 (Whetten et al. 2001). Following this, studies on angiosperms provided additional 584 information by deciphering the gelatinous layer (G-layer) deposition in the 585 so-called G-fibres during TW formation. Fasciclin-like arabinogalactan (FLA) 586 proteins and their corresponding transcripts have been intensively studied empha- 587 sizing their involvement as a hypothetical adhesion factor facilitating cellulose 588 deposition in the G-layer during TW formation in $P$. tremula $\times$ tremuloides 589 (Andersson-Gunnerås et al. 2003, 2006), P. tremula $\times$ alba (Lafarguette 590 et al. 2004), E. grandis (Qiu et al. 2008), E. nitens and A. thaliana (MacMillan 591 et al. 2010). Along with FLA studies, transcriptional mechanisms of saccharide 592 metabolism and deposition were also functionally dissected, even down to the cell 593 scale using microgenomic tools (Goué et al. 2008). Major works outlined the role of 594 sucrose synthase $($ SuSy) in P. tremula $\times$ alba (Déjardin et al. 2004), cellulose 595 synthase (CesA) in E. globulus (Paux et al. 2005), XET and xylo-glucan endo- 596 transglycosylase/hydrolase $(\mathrm{XTH})$ in $P$. tremula $\times$ tremuloides, Populus alba and 597 P. tremula (Nishikubo et al. 2007) and XET in L. tulipifera (Jin et al. 2011). 598

With the improvement of sequencing facilities and transcriptome-wide studies, 599 development of collections of ESTs related to wood formation transcriptomics were 600 set-up, some of them including data related to RW formation as for 601 $P$. tremula $\times$ tremuloides (Sterky et al. 2004), but also including expression data 602 in RW for several other poplar species (Sjodin et al. 2009), for P. abies (Koutaniemi 603 et al. 2007), for $P$. radiata (Ramos et al. 2012) and for P. pinaster (Villalobos 604 et al. 2012).

A striking point with timescale studies of RW formation is that very few reports 606 deal with early molecular events of the process. In other words, most of the 607 published works dealing with transcriptomics of RW formation, either gene- 608 targeted or genome-wide, focus at developmental stages when RW is already 609 histologically observable in the xylem. Precursor work in the field of the induction 610 
of RW does exist but is only gene-targeted at the moment. ZFP2 transcription factor was firstly reported in Juglans regia (Leblanc-Fournier et al. 2008) and P. tremula $\times$ alba (Martin et al. 2009). This ZFP2 is coined "mechano-sensitive" and addresses the xylem cell response to mechanical stress at a very early stage in a timely and structured manner in the transduction pathway to TW formation in trees, along with $\mathrm{TCH} 2$ and $\mathrm{TCH} 4$ as reported in $P$. tremula $\times$ alba from quantitative PCR studies (Martin et al. 2010). TCH4, reported as encoding for an XET in A. thaliana (Xu et al. 1995), draws attention to enzymatic-oriented cellulose modifications in the cell wall. The field of early RW induction, at the cell level and before any macroscopic tissue organization can be observed in the stem, is hopefully a must in any forthcoming experiments.

\subsubsection{Techniques for Proteome Measurement}

Proteomics is a powerful molecular tool for describing proteomes at the organelle, cell, organ or tissue levels and for showing the modifications of protein expression in response to environmental changes (Abbasi and Komatsu 2004). Proteomics completes the large-scale analysis of the transcriptome. On many occasions, the level of mRNA is not always correlated with protein expression level. One transcript may be translated into more than one protein because of alternative splicing or alternative post-translational modifications. In addition, post-translational modifications such as phosphorylation and glycosylation may modify protein activities and subcellular localization (Yan et al. 2005).

Although attempts have been made at identifying proteins whose abundance, localization, and/or post-transcriptional modifications are altered by gravistimulation, most studies were conducted on A. thaliana seedlings and tended to unravel the mechanisms that control root gravitropism (for review, see Harrison et al. 2008). As for the understanding of the response of tree shoots to gravity, both gymnosperm and angiosperm species should be considered separately since the structure and properties of $\mathrm{CW}$ are different from those of TW. Although studies have been conducted to elucidate wood formation in trees, few of them have addressed the problem at the proteomic level, and even less focussed on RW genesis.

Among the first global attempts to unravel xylogenesis in trees, two-dimensional (2D) electrophoresis has been used to characterize xylem maritime pine proteins (Costa et al. 1999) or seasonal changes in protein expression in wood-forming tissues of poplar (Minsbrugge et al. 2000). The first description of the proteome of maritime pine wood-forming tissue (identification of 175 proteins) was provided by Gion et al. (2005). The variations in the proteome of differentiating xylem collected from the top to the bottom of adult maritime pine ( $P$. pinaster) trees have provided a list of candidate genes for wood properties (Paiva et al. 2007). Using a large-scale approach, regeneration of the secondary vascular system in poplar was studied after peeling of the bark and sampling by scraping regenerating tissues (Juan et al. 2006). 
A dynamic view of the changes occurring during the juvenile wood formation in the 652 proteome of $E$. grandis has been provided using xylem tissues from 3- and 6-year- 653 old trees (Celedon et al. 2007). More recently, a focussed analysis of plasma 654 membrane proteomes from different tissues isolated from 3 to $4 \mathrm{~m}$ high poplar 655 trees identified 108 proteins that were specifically expressed in the xylem (Nilsson 656 et al. 2010). The authors proposed a schematic model for wood formation, inte- 657 grating proteins expressed in the xylem such as cellulose-synthesizing complex, 658 receptors, glucan sythase, AGPs, and enzymes of lignin biosynthesis. In particular 659 the thorough investigation of cellulose synthase complexes in differentiating 660 Populus xylem has been realized using complementary approaches including 661 laser microdissection, immunolocalization along with proteomic analysis (Song 662 et al. 2010).

With the aim of understanding TW induction or formation, proteomic analyses 664 have been conducted on Poplar and Eucalyptus. These species are used as models 665 in forest genetics and woody plant studies because they grow rapidly, they can be 666 genetically transformed and the size of their genome is relatively small (5 to 667 $6 \times 10^{8}$ bp) (Plomion et al. 2001). As for CW, different pine species, Sitka spruce 668 (Picea sitchensis) and Japanese cypress (C. obtusa) have been used because of their 669 economic and ecological interest. To investigate differentially expressed proteins in 670 response to gravity, most studies report 2D polyacrylamide gel electrophoresis 671 (PAGE) patterns and include identification of proteins by matrix-assisted laser 672 desorption/ionization-time of flight (MALDI-TOF), mass spectrometry (MS) or 673 by liquid chromatography coupled to tandem mass spectrometry (LC-MS/MS). 674 One study using Multidimensional Protein Identification Technology (MudPIT) 675 reported on the proteome of Populus developing xylem (Kalluri et al. 2009). The 676 proteins were extracted from subcellular fractions of xylem stems, enzymatically 677 digested and the resulting peptides were analysed using LC-MS/MS. However, this 678 study was not specifically addressing RW induction/formation. In the next para- 679 graphs, proteomic studies on TW induction/formation are first presented, followed 680 by data on CW. Depending on the studies, the gravistimulation design, the organs 681 and tissues used for protein extraction have been very different. In addition, studies 682 on TW formation after bending using constraining strings are also presented. 683 Because of the diversity of experimental designs, the synthesis of the results 684 remains problematic.

\subsubsection{Measured Changes in Proteome}

Azri et al. (2009) studied young poplars (14-20 internodes) inclined at $35^{\circ}$ from the 687 vertical axis. Whole internodes from the basal and apical regions of vertical and 688 gravistimulated stems were collected. The purpose of this experimental procedure 689 was to allow analysis of the differential expression caused by gravistimulation 690 between regions showing different motors for stem reorientation. The apical region 691 responds to inclination by differential growth due to elongation of primary tissues 692 
while reorientation is due to asymmetrical formation of RW at the base. After 45 min of gravistimulation, the stem showed no reorientation. After 1 week, RW was observed at the base of the stem. Differential protein expression was reported between inclined or non-inclined conditions and also between the regions of the stem. Among 300 protein spots, $40 \%$ showed significant changes after inclination. Sixty protein spots whose staining intensity was altered by gravistimulation were identified by mass spectrometry. These 60 proteins fell into a large range of functional categories. Interestingly, the patterns of expression of these selected proteins differed strongly between the conditions tested (apical and basal regions, $45 \mathrm{~min}$ and 1 week of inclination). At $45 \mathrm{~min}$ and 1 week, respectively, three and four proteins were similarly regulated by gravistimulation between the top and the basal regions. These observations suggested that different metabolisms and signaling pathways were involved in each region of the stem following a short (45 $\mathrm{min})$ or a long (1 week) exposure to gravistimulation. At $45 \mathrm{~min}$, before any visible reorientation of the stem, some of the proteins regulated by gravistimulation may be involved in graviperception. At the top of the stem (where reorientation will later occur through differential elongation of primary tissues), the results suggested the implication of ROS (regulation of oxidative stress-responsive enzymes). The regulation of actin and tubulin subunits, or microtubule-binding proteins showed the importance of cell wall-plasma membrane-cytoskeleton structural continuum for graviperception. Several proteins suggested some signaling via the endomembrane system and that calcium and phosphoinositides might act as cellular messengers (calreticulin, phosphatidyl inositol transfer protein SEC14). At the base of the stem (where orientation will later occur through the formation of RW), the most noticeable enzymes that were differentially expressed by gravistimulation were involved in lignin biosynthesis (phenylcoumaran benzylic ether reductase, S-adenosylmethionine synthase). However, members of the S-adenosyl-L-methionine-synthase gene family, which serve as universal methyl-group donors, are potentially involved in lignin as well as in ethylene biosynthesis pathways.

In Eucalyptus gunnii, proteins were extracted from xylem tissue harvested from a crooked tree. Two-dimensional gel electrophoresis images from normal and TW were compared showing that 12 proteins out of 140 proteins analysed were differentially expressed (Plomion et al. 2003). However, none of these proteins were identified.

A different approach was carried out by Kaku et al. (2009) who focused on the proteome of the G-layer in poplar TW. Leaning stems and branches from fieldgrown poplars were used as sources for isolation of G-layers from TW. Among the proteins separated by 2D gel electrophoresis, 108 were identified. Most abundant were lignin synthesis-related proteins although the $\mathrm{G}$ layer did not contain lignin itself. Cytoskeleton proteins, methionine synthesis-related proteins and cell wallrelated proteins were also identified. Lignification in TW is still a matter of debate. Andersson-Gunnerås et al. (2006) using a global analysis reported a decrease in monolignol biosynthesis in TW compared with normal wood. However, on-going lignification was observed during $\mathrm{G}$ layer deposition in the compound middle lamella, S1 and S2 layers in poplar TW (Yoshinaga et al. 2012). An assay based 
on protein cleavage isotope dilution mass spectroscopy (PC-IDMS) has been 738 developed for quantification of proteins regulating monolignol biosynthesis in 739 P. trichocarpa (Shuford et al. 2012) and could potentially bring valuable data to 740 decipher lignification in RW.

In conifers, $\mathrm{CW}$ is formed in response to gravitropic stimulus or environmental 742 disturbances such as prevailing winds, and "pushes" the stems toward a vertical 743 orientation. In the same way as for the TW studies, proteomic analyses of CW 744 formation concerned either developing $\mathrm{CW}$ or inclined stems where no $\mathrm{CW}$ had 745 been formed yet.

A comparative protein-based approach to identify proteins specifically 747 expressed in CW was conducted with branches of Sitka spruce (P. sitchensis) 748 (McDougall 2000). The developing xylem was sampled from the compression 749 and non-compression sides of the branches. The comparison of polypeptides 750 patterns by SDS-PAGE led to the identification of a laccase-type polyphenol 751 oxidase that was over-expressed in compression tissues. This enzyme is thought 752 to be involved in lignin biosynthesis.

On a larger scale, the identification of CW responsive proteins has been 754 conducted with a 22-year-old crooked maritime pine ( $P$. pinaster Ait.) (Plomion 755 et al. 2000). Wood samples were mechanically and chemically characterized by 756 measuring growth strains and lignin and cellulose contents, respectively. Of the 757 137 spots studied, $19 \%$ were associated with growth strain effect. The results 758 indicated the importance of ethylene in CW formation. The implication of 759 1-aminocyclopropane-1-carboxylate (ACC) oxidase which catalyses the final reac- 760 tion of the ethylene biosynthetic pathway in CW formation has also been suggested 761 by Yuan et al. (2010). These authors examined PtACO1 and PtACO1-like 762 (encoding putative ACC oxidases) transcript levels by quantitative PCR in loblolly 763 pine seedling stems that were bent to a $90^{\circ}$ angle using constraining strings. They 764 observed an increase in these transcripts levels starting at $30 \mathrm{~min}$ and peaking at $3 \mathrm{~h} 765$ after bending. PtACO1-like transcripts were higher in CW than in opposite wood 766 (OW). Besides, Plomion et al. (2000) have found that lignin biosynthesis was also 767 affected during CW formation and that enzymes involved in Krebs cycle, sucrose 768 and starch metabolism were up-regulated.

In another study, sampling of compression and OW was done with 16-year-old 770 maritime pines bent to a $15^{\circ}$ angle by tying their trunks to neighbouring trees for 771 2 years (Gion et al. 2005). Other types of wood were also analysed (juvenile and 772 mature woods, early and late woods). The clustering of 215 proteins identified over 773 the six types of wood was presented. It appeared that $20 \%$ of the identified proteins 774 exhibited distinctive expression patterns between CW and OW. Profilin, actin and 775 nucleoside diphosphate kinase, 40S ribosomal S12 proteins were under-expressed 776 in $\mathrm{CW}$.

LC-MS analysis of Golgi-enriched membrane fraction from developing 778 $P$. radiata $\mathrm{CW}$ has been done following in-solution digestion with trypsin (Mast 779 et al. 2010). CW was sampled from 6-year-old trees in late summer to maximize the 780 identification of proteins involved in secondary cell wall formation. As expected 781 most proteins detected were involved not only in cell wall synthesis (i.e. cellulose 782 
synthase, laccase, phenyl alanine ammonia-lyase) but also in hormone biosynthesis and signaling (i.e. auxin-induced proteins, ACC synthase) and stress and defence response. Within this last putative functional category, numerous receptors were found (CC-NBS-LRR protein, NBS/LRR, TIR/NBS, TIR/NBS/LRR disease resistance protein).

Gravitropism is not the only process that determines stem orientation; phototropism is also an important factor that can lead to RW production. The interaction between these two processes has not been extensively studied in trees. Herrera et al. (2010) have presented a proteomic analysis of inclined pine seedlings submitted to an orthogonal light source. However, the apices were collected instead of the basal part of the stem where undergoing secondary growth takes place. Thus this study mainly identified differentially expressed proteins in the primary response to stem tilting.

Proteomic studies have been realized with different organs and tissues (stem, branches, whole internodes, xylem, G layer) from seedlings to trees aged from 2 month-old to 22 year-old. In some cases the plants were inclined or mechanically bent and the proteome was analysed after varying times depending on the study (from 45 min to days or weeks). In other cases, aged plants showing RW were used. The problem is to discriminate between overlapping events such as induction, signal transduction (first events following stimulation) in the stimulated cells which are not clearly identified yet, reorientation of cambial cell programming, and differentiation of newly formed cells in the developing xylem. In addition, perception of the gravitropic stimulus and response probably occur in different cells. The proteomic approach has been executed either on whole internodes or on xylem tissue which may not contain the perceptive cells. Among the proteins listings published, large functional categories appear such as primary metabolism, cytoskeleton organization and biogenesis, cell wall synthesis, hormone biosynthesis and signaling. However, the role of most proteins is still hypothetical. Focused studies are needed to evaluate the role of the proteins brought forward by global proteomic analyses.

\subsubsection{Metabolomics and RW Formation}

Metabolomics is a global approach used in biology for systematic metabolite quantification, a metabolite being any intermediate or product of the metabolism, e.g. amino acids, carbohydrates, hormones, and many more. Although several studies targeted some metabolites related to carbon and secondary metabolism that potentially play a role in RW formation (Yeh et al. 2005, 2006; Shi and Li 2012), "without a priori" approaches have been marginally exploited in this field. To date, only Andersson-Gunnerås et al. (2006) have published work using this technique. A combination of metabolomics and transcriptomics recently gave precious insights on the Arabidopsis gravitropism and phototropism interplay (Millar and Kiss 2013). Andersson-Gunnerås et al. (2006) used a similar approach 
to gain access to the G-layer formation in poplar TW induced after 11 days bending. 824 Conclusions from biochemical measurements follow predictions coherent with 825 gene expression showing in TW: an increased activity of cellulose synthesis and 826 pectin degradation-related genes while those involved in lignin biosynthesis are 827 decreased. An advantage of their transcriptomic approach consists in fine identifi- 828 cation of differentially expressed genes from multigenic families, thus refining the 829 implication of gene candidates individually. Based on their expression and meta- 830 bolic profiles, they propose extensive relational models for carbon metabolism and 831 lignin biosynthesis in TW. Despite the importance of this work that provides a 832 coherent framework based on quantitative and qualitative data on TW chemistry 833 and gene expression, the earlier steps remain a matter of discovery.

\subsection{Concluding Remarks}

The formation of RW allows woody structures to adapt their position in response to 836 gravitational and mechanical stimulation and/or a change in the light environment. 837 The deciphering of the molecular mechanisms underlying this particular growth 838 response is complex. It requires at the very least, tree models with sequenced 839 genomes, which allow global approaches such as transcriptomics and proteomics. 840 Functional genomics which aims to elucidate the function of proteins encoded by 841 candidate genes is limited by a scarcity of mutants and the long generation times of 842 forest trees. In the face of these complex challenges, Wyatt et al. (2010) presented 843 A. thaliana as a model for a molecular and genetic analysis of the mechanisms of 844 TW formation. In addition, RW formation having many external or internal causal 845 agents (gravity, light, interactions of both stimuli, inherent patterning mechanisms), 846 it is difficult to set up an experimental design that addresses the impact of one 847 particular stimulus in trees. Most studies utilized inclined trees in greenhouse 848 conditions, although both phototropic and gravitropic reactions occurred in such 849 conditions. Signalisation pathways leading to tree stature adjustments are different 850 whether starting from a light or a gravi-mechanical stimulus. For a short period of 851 time, dark or isotropic light conditions could be used to gain insight into gravitropic 852 signalisation pathway leading to RW formation. Moreover the issues around stak- 853 ing also need to be considered since different molecular pathways may be induced 854 if stem deformation is allowed or not.

Hypotheses about perception of gravistimulation were previously defined 856 through studies using $A$. thaliana mutants. However, in trees the question about 857 the role of amyloplasts remains since starch is present in high level and everywhere 858 in old woody structures. In trees, the tissue/cell that perceives gravistimulation is 859 not clearly identified. As for the early events of signal transduction, one has to 860 emphasize that very few studies were done at the very beginning of induction of 861 RW, before any macroscopic observation of RW formation. Mechano-receptors 862 involved in RW induction have still to be characterized. Global approaches suggest 863 the role of calcium and ROS as second messengers and some signaling via the 864 
endomembrane system and phosphoinositides. Although components of the signaling network have been identified through global analyses, the way they relate to one another in space and time is still unknown. Wyatt and Kiss (2013) speak about a "more or less amorphous gray cloud" when relating to the understanding of the signaling network. More precision could come from microdissection of chosen tissues or cells prior to molecular investigations. Typically, the early events of signal transduction are supposed to lead to hormonal response (i.e. synthesis, degradation, redistribution, reallocation, compartmentalization, and so on) that will finally provoke the growth and cell differentiation response. The involvement of ethylene gibberellin and auxin has been discussed but more studies are needed in order to decipher hormone signaling crosstalk in RW induction at the cell level, and also at the organ and whole plant level. For example, Azri et al. (2009) suggested that different signaling pathways occurred at the top and the base of a tilted poplar stems.

In conclusion, global approaches reveal the complexity of the RW induction both on a temporal scale and as a function of the location in the tree. Therefore, although the transcriptional network, the organization of protein synthesis and the subsequent hormonal response at the whole tree level is still unknown, the beginning of an understanding of how trees manipulate RW formation to solve their mechanical requirements is emerging.

\section{References}

Abbasi FM, Komatsu S (2004) A proteomic approach to analyze salt-responsive proteins in rice leaf sheath. Proteomics 4:2072-2081

Abeles FB, Morgan PW, Saltveit ME Jr (1992) Ethylene in plant biology, 2nd edn. Academic, San Diego

Allen GJ, Muir SR, Sanders D (1995) Release of $\mathrm{Ca}^{2+}$ from individual plant vacuoles by both InsP3 and cyclic ADP-ribose. Science 268:735-737

Allona I, Quinn M, Shoop E, Swope K, Saint Cyr S, Carlis J, Riedl J, Retzel E, Campbell MM, Sederoff R, Whetten RW (1998) Analysis of xylem formation in pine by cDNA sequencing. Proc Natl Acad Sci U S A 95:9693-9698

Almeras T, Fournier M (2009) Biomechanical design and long-term stability of trees: morphological and wood traits involved in the balance between weight increase and the gravitropic reaction. J Theor Biol 256:370-381

Almeras T, Costes E, Salles JC (2004) Identification of biomechanical factors involved in stem shape variability between apricot tree varieties. Ann Bot 93:455-468

Andersson-Gunnerås S, Hellgren JM, Björklund S, Regan S, Moritz T, Sundberg B (2003) Asymmetric expression of a poplar ACC oxidase controls ethylene production during gravitational induction of tension wood. Plant J 34:339-349

Andersson-Gunnerås S, Mellerowicz EJ, Love J, Segerman B, Ohmiya Y, Coutinho PM, Nilsson P, Henrissat B, Moritz T, Sundberg B (2006) Biosynthesis of cellulose-enriched tension wood in Populus: global analysis of transcripts and metabolites identifies biochemical and developmental regulators in secondary wall biosynthesis. Plant J 45:144-165

Azri W, Chambon C, Herbette S, Brunel N, Coutand C, Leplé JC, Ben Rejeb I, Ammar S, Julien JL, Roeckel-Drevet P (2009) Proteome analysis of apical and basal regions of poplar stems under gravitropic stimulation. Physiol Plant 136:193-208 
Azri W, Brunel N, Franchel J, Ben Rejeb I, Jacquot JP, Julien J-L, Herbette S, Roeckel-Drevet P 910 (2013) Putative involvement of thioredoxin $h$ in early response to gravitropic stimulation of 911 poplar stems. J Plant Physiol 170:707-711

Baba K, Adachi K, Take T, Yokoyama T, Ito T, Nakamura T (1995) Induction of tension wood in 913 $\mathrm{GA}_{3}$-treated branches of the weeping type of Japanese cherry, Prunus spachiana. Plant Cell 914 Physiol 36:983-988

Baluška F, Volkmann D (2011) Mechanical aspects of gravity-controlled growth, development 916 and morphogenesis. In: Wojtaszek P (ed) Mechanical integration of plant cells and plants, 917 Signaling and communication in plants. Springer-Verlag GmbH, Heidelberg, pp 195-222 918

Baluška F, Šamaj J, Wojtaszek P, Volkmann D, Menzel D (2003) Cytoskeleton-plasma mem- 919 brane-cell wall continuum in plants. Emerging links revisited. Plant Physiol 133:482-491 920

Bastien R, Bohr T, Moulia B, Douady S (2013) Unifying model of shoot gravitropism reveals 921 proprioception as a central feature of posture control in plants. Proc Natl Acad Sci U S A 922 110:755-760

Bedon F, Grima-Pettenati J, Mackay J (2007) Conifer R2R3-MYB transcription factors: sequence 924 analyses and gene expression in wood-forming tissues of white spruce (Picea glauca). BMC 925 Plant Biol 7:17

Berthier S, Stokes A (2005) Phototropic response induced by wind loading in Maritime pine 927 seedlings (Pinus pinaster Ait.). J Exp Bot 56:851-856

Björklund S, Antti H, Uddestrand I, Moritz T, Sundberg B (2007) Cross-talk between gibberellin 929 and auxin in development of Populus wood: gibberellin stimulates polar auxin transport and 930 has a common transcriptome with auxin. Plant J 52:499-511 931

Booth IR, Blount P (2012) The MscS and MscL families of mechanosensitive channels act as 932 microbial emergency release valves. J Bacteriol 194:4802-4809 933

Braam J (2005) In touch: plant responses to mechanical stimuli. New Phytol 165:373-389 934

Celedon PAF, de Andrade A, Xavier Meireles KG, Gallo de Carvalho MC, Gomes Caldas DG, 935 Moon DH, Tozelli Carneiro R, Franceschini LM, Oda S, Labate CA (2007) Proteomic analysis 936 of the cambial region in juvenile Eucalyptus grandis at three ages. Proteomics 7:2258-2274 937

Collet C, Fournier M, Ningre F, Hounzandji AP, Constant T (2011) Growth and posture control 938 strategies in Fagus sylvatica and Acer pseudoplatanus saplings in response to canopy distur- 939 bance. Ann Bot 107:1345-1353 940

Correll MJ, Kiss JZ (2002) Interactions between gravitropism and phototropism in plants. J Plant 941 Growth Regul 21:89-101

Cosgrove DJ, Hedrich R (1991) Stretch-activated chloride, potassium, and calcium channels 943 coexisting in plasma membranes of guard cells of Vicia faba L. Planta 186:143-153 944

Costa P, Pionneau C, Bauw G, Dubos C, Bahrmann N, Kremer A, Frigerio J-M, Plomion C (1999) 945 Separation and characterization of needle and xylem maritime pine proteins. Electrophoresis 946 20:1098-1108

Coste B, Mathur J, Schmidt M, Earley TJ, Ranade S, Petrus MJ, Dubin AE, Patapoutian A (2010) 948 Piezo1 and Piezo2 are essential components of distinct mechanically activated cation channels. 949 Science 330:55-60

Coste B, Xiao B, Santos JS, Syeda R, Grandl J, Spencer KS, Kim SE, Schmidt M, Mathur J, 951 Dubin AE, Montal M, Patapoutian A (2012) Piezo proteins are pore-forming subunits of 952 mechanically activated channels. Nature 483:176-181 953

Coutand C, Fournier M, Moulia B (2007) The gravitropic response of poplar trunks: key roles of 954 prestressed wood regulation and the relative kinetics of cambial growth versus wood matura- 955 tion. Plant Physiol 144:1166-1180

Decreux A, Messiaen J (2005) Wall-associated kinase WAK1 interacts with cell wall pectins in a 957 calcium-induced conformation. Plant Cell Physiol 46:268-278

Déjardin A, Leplé J-C, Lesage-Descauses M-C, Costa G, Pilate G (2004) Expressed sequence tags 959 from poplar wood tissues - a comparative analysis from multiple libraries. Plant Biol 6:55-64 960

Ding JP, Pickard BG (1993) Modulation of mechanosensitive calcium-selective cation channels 961 by temperature. Plant J 3:713-720 
1001 Haswell ES, Phillips R, Rees DC (2011) Mechanosensitive channels: what can they do and how do 1002 they do it? Structure 19:1356-1369

1003 He ZH, Fujiki M, Kohorn BD (1996) A cell wall-associated, receptor-like protein kinase. J Biol 1004 Chem 271:19789-19793

1005 He ZH, Cheeseman I, He D, Kohorn BD (1999) A cluster of five cell wall-associated receptor 1006 kinase genes, Wakl-5, are expressed in specific organs of Arabidopsis. Plant Mol Biol 1007 39:1189-1196

1008 Hellgren JM, Olofsson K, Sundberg B (2004) Patterns of auxin distribution during gravitational 1009 induction of reaction wood in poplar and pine. Plant Physiol 135:212-220

1010 Hématy K, Sado PE, Van Tuinen A, Rochange S, Desnos T, Balzergue S, Pelletier S, Renou JP, 1011 Höfte $\mathrm{H}$ (2007) A receptor-like kinase mediates the response of Arabidopsis cells to the 1012 inhibition of cellulose synthesis. Curr Biol 17:922-931

1013 Herrera R, Krier C, Lalanne C, Ba EHM, Stokes A, Salin F, Fourcaud T, Claverol S, Plomion C 1014 (2010) (Not) keeping the stem straight: a proteomic analysis of maritime pine seedlings 1015 undergoing phototropism and gravitropism. BMC Plant Biol 10:217-229 
Hohm T, Preuten T, Fankhauser C (2013) Phototropism: translating light into directional growth. 1016 Am J Bot 100:47-59 1017

Hrabak EM, Chan CWM, Gribskov M, Harper JF, Choi JH, Halford N, Luan S, Nimmo HG, 1018 Sussman MR, Thomas M, Walker-Simmons K, Zhu JK, Harmon AC (2003) The Arabidopsis 1019 CDPK-SnRK superfamily of protein kinases. Plant Physiol 132:666-680 1020

Humphrey TV, Bonetta DT, Goring DR (2007) Sentinels at the wall: cell wall receptors and 1021 sensors. New Phytol 176:7-21 1022

Jin H, Do J, Moon D, Noh EW, Kim W, Kwon M (2011) EST analysis of functional genes 1023 associated with cell wall biosynthesis and modification in the secondary xylem of the yellow 1024 poplar (Liriodendron tulipifera) stem during early stage of tension wood formation. Planta 1025 234:959-977 1026

Jones-Rhodes MW, Bartel DP, Barterl B (2006) MicroRNAs and their regulatory roles in plants. 1027 Annu Rev Plant Biol 57:19-53 1028

Jourez B, Avella-Shaw T (2003) Effet de la durée d'application d'un stimulus gravitationnel sur la 1029 formation de bois de tension et de bois opposé dans de jeunes pousses de peuplier (Populus 1030 euramericana cv 'Ghoy'). Ann For Sci 60:31-41 1031

Juan D, Hong-Li X, De-Qiang Z, Xin-Qinag H, Min-Jie W, Ying-Zhang L, Ke-Ming C, Meng-Zhu L 1032 (2006) Regeneration of the secondary vascular system in poplar as a novel system to investigate 1033 gene expression by a proteomic approach. Proteomics 6:881-895 1034

Kaku T, Serada S, Baba K, Tanaka F, Hayashi T (2009) Proteomic analysis of the G-layer in poplar 1035 tension wood. J Wood Sci 55:250-257 1036

Kalluri UC, Hurst GB, Lankford PK, Ranjan P, Pelletier DA (2009) Shotgun proteome profile of 1037 Populus developing xylem. Proteomics 9:4871-4880 1038

Kern VD, Sack FD (1999) Irradiance-dependent regulation of gravitropism by red light in 1039 protonemata of the moss Ceratodon purpureus. Planta 209:299-307 1040

Kim SE, Coste B, Chadha A, Cook B, Patapoutian A (2012) The role of Drosophila Piezo in 1041 mechanical nociception. Nature 483:209-212 1042

Knight MR, Campbell AK, Smith SM, Trewavas AJ (1991) Transgenic plant aequorin reports the 1043 effects of touch and cold-shock and elicitors on cytoplasmic calcium. Nature 352:524-526 1044

Knight MR, Smith SM, Trewavas AJ (1992) Wind-induced plant motion immediately increases 1045 cytosolic calcium. Proc Natl Acad Sci U S A 89:4967-4971 1046

Kojima M, Becker VK, Altaner CM (2012) An unusual form of reaction wood in Koromiko [Hebe 1047 salicifolia G.Forst. (Pennell)], a southern hemisphere angiosperm. Planta 235:1315-1330 1048

Koutaniemi S, Warinowski T, Karkonen A, Alatalo E, Fossdal CG, Saranpaa P, Laakso T, 1049 Fagerstedt KV, Simola LK, Paulin L, Rudd S, Teeri TH (2007) Expression profiling of the 1050 lignin biosynthetic pathway in Norway spruce using EST sequencing and real-time RT-PCR. 1051 Plant Mol Biol 65:311-328

Kurusu T, Kuchitsu K, Nakano M, Nakayama Y, Iida H (2013) Plant mechanosensing and $\mathrm{Ca}^{2+} 1053$ transport. Trends Plant Sci 18:227-233 1054

Lafarguette F, Leplé J-C, Déjardin A, Laurans F, Costa G, Lesage-Descauses M-C, Pilate G (2004) 1055 Poplar genes encoding fasciclin-like arabinogalactan proteins are highly expressed in tension 1056 wood. New Phytol 164:107-121 1057

Lally D, Ingmire P, Tong HY, He ZH (2001) Antisense expression of a cell wall-associated protein 1058 kinase, WAK4, inhibits cell elongation and alters morphology. Plant Cell 13:1317-1331 1059

Leblanc-Fournier N, Coutand C, Crouzet J, Brunel N, Lenne C, Moulia B, Julien J-L (2008) Jr- 1060 ZFP2, encoding a Cys2/His2-type transcription factor, is involved in the early stages of the 1061 mechano-perception pathway and specifically expressed in mechanically stimulated tissues in 1062 woody plants. Plant Cell Environ 31:715-726

Lindner H, Müller LM, Boisson-Dernier A, Grossniklaus U (2012) CrRLK1L receptor-like 1064 kinases: not just another brick in the wall. Curr Opin Plant Biol 15:659-669 1065

Little CHA, Savidge RA (1987) The role of plant-growth regulators in forest tree cambial growth. 1066 Plant Growth Regul 6:137-169 
1068 Love J, Björklund S, Vahala J, Hertzberg M, Kangasjärvi J, Sundberg B (2009) Ethylene is an 1069 endogenous stimulator of cell division in the cambial meristem of Populus. Proc Natl Acad Sci 1070 U S A 106:5984-5986

1071 Lu S, Sun Y-H, Shi R, Clark C, Li L, Chiang VL (2005) Novel and mechanical stress-responsive 1072 microRNAs in Populus trichocarpa that are absent from Arabidopsis. Plant Cell 17:2186-2205 1073 Lu S, Li L, Yi X, Joshi CP, Chiang VL (2008) Differential expression of three Eucalyptus 1074 secondary cell wall-related cellulose synthase genes in response to tension stress. J Exp Bot 1075 59:681-695

1076 MacMillan CP, Mansfield SD, Stachurski ZH, Evans R, Southerton SG (2010) Fasciclin-like 1077 arabinogalactan proteins: specialization for stem biomechanics and cell wall architecture in 1078 Arabidopsis and Eucalyptus. Plant J 62:689-703

1079 Marín-González E, Suárez-López P (2012) "And yet it moves”: cell-to-cell and long-distance 1080 signaling by plant microRNAs. Plant Sci 196:18-30

1081 Martin L, Leblanc-Fournier N, Azri W, Lenne C, Henry C, Coutand C, Julien J-L (2009) 1082 Characterization and expression analysis under bending and other abiotic factors of PtaZFP2, 1083 a poplar gene encoding a Cys2/His2 zinc finger protein. Tree Physiol 29:125-136

1084 Martin L, Leblanc-Fournier N, Julien J-L, Moulia B, Coutand C (2010) Acclimation kinetics of 1085 physiological and molecular responses of plants to multiple mechanical loadings. J Exp Bot 1086 61:2403-2412

1087 Mast S, Peng L, Jordan W, Flint H, Phillips L, Donaldson L, Strabala TJ, Wagner A (2010) 1088 Proteomic analysis of membrane preparations from developing Pinus radiata compression 1089 wood. Tree Physiol 30:1456-1468

1090 Matsuzaki J, Masumori M, Tange T (2006) Stem phototropism of trees: a possible significant 1091 factor in determining stem inclination on forest slopes. Ann Bot 98:573-581

1092 Matsuzaki J, Masumori M, Tange T (2007) Phototropic bending of non-elongating and radially 1093 growing woody stems results from asymmetrical xylem formation. Plant Cell Environ 1094 30:646-653

1095 Mauriat M, Moritz T (2009) Analyses of GA20ox- and GID1-over-expressing aspen suggest that 1096 gibberellins play two distinct roles in wood formation. Plant J 58:989-1003

1097 McDougall GJ (2000) A comparison of proteins from the developing xylem of compression and 1098 non-compression wood of branches of Sitka spruce (Picea sitchensis) reveals a differentially 1099 expressed laccase. J Exp Bot 51:1395-1401

1100 Mellerowicz EJ, Immerzeel P, Hayashi T (2008) Xyloglucan: the molecular muscle of trees. Ann 1101 Bot 105:659-665

1102 Millar KD, Kiss JZ (2013) Analyses of tropistic responses using metabolomics. Am J Bot 1103 100:79-90

1104 Minsbrugge KV, Meyermans H, Van Montagu M, Bauw G, Boerjan W (2000) Wood formation in 1105 poplar: identification, characterization, and seasonal variation of xylem proteins. Planta $1106 \quad 210: 589-598$

1107 Monshausen GB, Haswell ES (2013) A force of nature: molecular mechanisms of 1108 mechanoperception in plants. J Exp Bot. doi:10.1093/jxb/ert204 (Epub ahead of print)

1109 Mori IC, Schroeder JI (2004) Reactive oxygen species activation of plant $\mathrm{Ca}^{2+}$ channels. Signaling 1110 mechanisms in polar growth, hormone transduction, stress signaling, and hypothetically 1111 mechanotransduction. Plant Physiol 135:702-708

1112 Morita MT (2010) Directional gravity sensing in gravitropism. Annu Rev Plant Biol 61:705-720 1113 Morita MT, Kato T, Nagafusa K, Saito C, Ueda T, Nakano A, Tasaka M (2002) Involvement of the 1114 vacuoles of the endodermis in the early process of shoot gravitropism in Arabidopsis. Plant 1115 Cell 14:47-56

1116 Moulia B, Fournier M (2009) The power and control of gravitropic movements in plants: a 1117 biomechanical and systems biology view. J Exp Bot 60:461-486

1118 Moulia B, Coutand C, Lenne C (2006) Posture control and skeletal mechanical acclimation in 1119 terrestrial plants: implications for mechanical modeling of plant architecture. Am J Bot 1120 93:1477-1489 
Moulia B, Der Loughian C, Bastien R, Martin L, Rodríguez M, Gourcilleau D, Barbacci A, 1121 Badel E, Franchel J, Lenne C, Roeckel-Drevet P, Allain JM, Frachisse JM, de Langre E, 1122 Coutand C, Leblanc-Fournier N, Julien JL (2011) Integrative mechanobiology of growth and 1123 architectural development in changing mechanical environments. In: Wojtaszek P 1124 (ed) Mechanical integration of plant cells and plants, Signaling and communication in plants. 1125 Springer-Verlag GmbH, Heidelberg, pp 269-302

Moyle R, Schrader J, Stenberg A, Olsson O, Saxena S, Sandberg G, Bhalerao RP (2002) 1127 Environmental and auxin regulation of wood formation involves members of the Aux/IAA 1128 gene family in hybrid aspen. Plant J 31:675-685

Nakagawa Y, Katagiri T, Shinozaki K, Qi Z, Tatsumi H, Furuichi T (2007) Arabidopsis plasma 1130 membrane protein crucial for $\mathrm{Ca}^{2+}$ influx and touch sensing in roots. Proc Natl Acad Sci U S A 1131 104:3639-3644

Nakamura T (2003) Control of morphogenesis of woody plant by gravity on earth. Biol Sci Space 1133 $17: 144-148$

Nakamura T, Saotome M, Ishiguro Y, Itoh R, Higurashi S, Hosono M, Ishii Y (1994) The effects of 1135 $\mathrm{GA}_{3}$ on weeping of growing shoots of the Japanese cherry, Prunus spachiana. Plant Cell 1136 Physiol 35:523-527

Nieminen K, Robischon M, Immanen J, Helariutta Y (2012) Towards optimizing wood develop- 1138 ment in bioenergy trees. New Phytol 194:46-53

Nilsson R, Bernfur K, Gustavsson N, Bygdell J, Wingsle G, Larsson C (2010) Proteomics of 1140 plasma membranes from poplar trees reveals tissue distribution of transporters, receptors, and 1141 proteins in cell wall formation. Mol Cell Proteomics 9:368-387

Nishikubo N, Awano T, Banasiak A, Bourquin V, Ibatullin F, Funada R, Brumer H, Teeri TT, 1143 Hayashi T, Sundberg B, Mellerowicz EJ (2007) Xyloglucan endo-transglycosylase (XET) 1144 functions in gelatinous layers of tension wood fibers in poplar-a glimpse into the mechanism 1145 of the balancing act of trees. Plant Cell Physiol 48:843-855

Nugroho WD, Yamagishi Y, Nakaba S, Fukuhara S, Begum S, Marsoem SN, Ko JH, Jin HO, 1147 Funada R (2012) Gibberellin is required for the formation of tension wood and stem 1148 gravitropism in Acacia mangium seedlings. Ann Bot 110:887-895 1149

Nugroho WD, Nakaba S, Yamagishi Y, Begum S, Marsoem SN, Ko JH, Jin HO, Funada R (2013) 1150 Gibberellin mediates the development of gelatinous fibres in the tension wood of inclined 1151 Acacia mangium seedlings. Ann Bot 112:1321-1329. doi:10.1093/aob/mct198 (Epub ahead of 1152 print)

1153

Osakabe Y, Kawaoka A, Nishikubo N, Osakabe K (2012) Responses to environmental stresses in 1154 woody plants: key to survive and longevity. J Plant Res 125:1-10 1155

Paiva JAP, Gracès M, Alves A, Garnier-Géré P, Rodrigues JC, Lalanne C, Porcon S, Le Provost G, 1156 da Silva Perez D, Brach J, Frigerio J-M, Claverol S, Barré A, Fevereiro P, Plomion C (2007) 1157 Molecular and phenotypic profiling from the base to the crown in maritime pine wood-forming 1158 tissue. New Phytol 178:283-301

Paux E, Carocha V, Marques C, Mendes de Sousa A, Borralho N, Sivadon P, Grima-Pettenati J 1160 (2005) Transcript profiling of Eucalyptus xylem genes during tension wood formation. New 1161 Phytol 167:89-100

Perera IY, Heilmann I, Chang SC, Boss WF, Kaufman PB (2001) A role for inositol 1,4,5- 1163 trisphosphate in gravitropic signaling and the retention of cold-perceived gravistimulation of 1164 oat shoot pulvini. Plant Physiol 125:1499-1507 1165

Pilate G, Chabbert B, Cathala B, Yoshinaga A, Leple' J-C, Laurans F, Lapierre C, Ruel K (2004) 1166 Lignification and tension wood. C R Biol 327:889-901 1167

Pivetti CD, Yen MR, Miller S, Busch W, Tseng YH, Booth IR, Saier MH (2003) Two families of 1168 mechanosensitive channel proteins. Microbiol Mol Biol Rev 67:66-85 1169

Plieth C, Trewavas AJ (2002) Reorientation of seedlings in the earth's gravitational field induces 1170

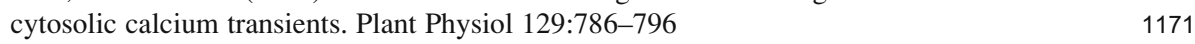


1172 Plomion C, Pionneau C, Brach J, Costa P, Baillères H (2000) Compression wood-responsive 1173 proteins in developing xylem of maritime pine (Pinus pinaster Ait.). Plant Physiol 1174 123:959-969

1175 Plomion C, Leprovost G, Stokes A (2001) Wood formation in trees. Plant Physiol 127:1513-1523 1176 Plomion C, Pionneau C, Baillères H (2003) Analysis of protein expression along the normal to 1177 tension wood gradient in Eucalyptus gunnii. Holzforschung 57:353-358

1178 Pruyn ML (1997) Thigmomorphogenesis: responses of two Populus hybrids to mechanical stress. 1179 MSc. Thesis, Michigan State University, East Lansing, MI, $90 \mathrm{p}$

1180 Pruyn ML, Ewers BJ, Telewski FW (2000) Thigmomorphogenesis: changes in the morphology 1181 and mechanical properties of two Populus hybrids in response to mechanical perturbation. Tree 1182 Physiol 20:535-540

1183 Qin SY, Hu D, Matsumoto K, Takeda K, Matsumoto N, Yamaguchi Y, Yamamoto K (2012) 1184 Malectin forms a complex with ribophorin I for enhanced association with misfolded glyco1185 proteins. J Biol Chem 287:38080-38089

1186 Qiu D, Wilson IW, Gan S, Washusen R, Moran GF, Southerton SG (2008) Gene expression in 1187 Eucalyptus branch wood with marked variation in cellulose microfibril orientation and lacking 1188 G-layers. New Phytol 179:94-103

1189 Ramos P, Le Provost G, Gantz C, Plomion C, Herrera R (2012) Transcriptional analysis of 1190 differentially expressed genes in response to stem inclination in young seedlings of pine. 1191 Plant Biol 14:923-933

1192 Savidge RA, Mutumba GM, Heald JK, Wareing PF (1983) Gas chromatography-mass spectros1193 copy identification of 1-aminocyclopropane-1-carboxylic acid in compression wood vascular 1194 cambium of Pinus contorta Dougl. Plant Physiol 71:434-436

1195 Serpe MD, Nothnagel EA (1995) Fractionation and structural characterization of arabinogalactan1196 proteins from the cell wall of rose cells. Plant Physiol 109:1007-1016

1197 Shi J, Li J (2012) Metabolites changes in inclined stem. BioResources 7:3463-3475

1198 Shiu SH, Bleecker AB (2001) Plant receptor-like kinase gene family: diversity, function, and 1199 signaling. Sci STKE 2001:re22

1200 Shuford CM, Li Q, Sun Y-H, Chen H-C, Wang J, Shi R, Sederoff RR, Chaing VL, Muddiman DC 1201 (2012) Comprehensive quantification of monolignol-pathway enzymes in Populus trichocarpa 1202 by protein cleavage isotope dilution mass spectrometry. J Proteome Res 11:3390-3404

1203 Sierra de Grado R, Pando V, Martinez-Zurimendi P, Penalvo A, Bascones E, Moulia B (2008) 1204 Biomechanical differences in the stem straightening process among Pinus pinaster prove1205 nances. A new approach for early selection of stem straightness. Tree Physiol 28:835-846

1206 Sjodin A, Street NR, Sandberg G, Gustafsson P, Jansson S (2009) The Populus genome integrative 1207 explorer (PopGenIE): a new resource for exploring the Populus genome. New Phytol 1208 182:1013-1025

1209 Song D, Shen J, Li L (2010) Characterization of cellulose synthase complexes in Populus xylem 1210 differentiation. New Phytol 187:777-790

1211 Spurr S, Hyvärinen M (1954) Compression wood in conifers as a morphogenetic phenomenon. Bot 1212 Rev 20:551-560

1213 Sterky F, Bhalerao RR, Unneberg P, Segerman B, Nilsson P, Brunner AM, Charbonnel-Campaa L, 1214 Lindvall JJ, Tandre K, Strauss SH, Sundberg B, Gustafsson P, Uhlen M, Bhalerao RP, 1215 Nilsson O, Sandberg G, Karlsson J, Lundeberg J, Jansson S (2004) A Populus EST resource 1216 for plant functional genomics. Proc Natl Acad Sci U S A 101:13951-13956

1217 Strohm AK, Baldwin KL, Masson PH (2012) Multiple roles for membrane-associated protein 1218 trafficking and signaling in gravitropism. Front Plant Sci 3:274

1219 Telewski FW (1989) Structure and function of flexure wood in Abies fraseri. Tree Physiol $1220 \quad 5: 113-122$

1221 Telewski FW (2006) A unified hypothesis of mechanoperception in plants. Am J Bot 1222 93:1466-1476 
Thibaut B, Gril J, Fournier M (2001) Mechanics of wood and trees: some new highlights for an old story. Comptes Rendus de l'Académie des Sciences Serie II Fascicule B-Mécanique 329:701-716

Timell TE (1986) Compression wood in gymnosperms. Springer, Berlin, $2150 \mathrm{p}$

1223

1224

1225

1226

Toyota M, Gilroy S (2013) Gravitropism and mechanical signaling in plants. Am J Bot 1227 100:111-125

Toyota M, Furuichi T, Tatsumi H, Sokabe M (2008) Cytoplasmic calcium increases in response to 1229 changes in the gravity vector in hypocotyls and petioles of Arabidopsis seedlings. Plant Physiol 1230 146:505-514

1231

Toyota M, Ikeda N, Sawai-Toyota S, Kato T, Gilroy S (2013) Amyloplast displacement is 1232 necessary for gravisensing in Arabidopsis shoots as revealed by a centrifuge microscope. 1233 Plant J. doi:10.1111/tpj.12324

1234

Ursache R, Nieminen K, Helariutta Y (2013) Genetic and hormonal regulation of cambial 1235 development. Physiol Plant 147:36-45

Vahala J, Felten J, Love J, Gorzsás A, Gerber L, Lamminmäki A, Kangasjärvi J, Sundberg B 1237 (2013) A genome-wide screen for ethylene-induced ethylene response factors (ERFs) in hybrid 1238 aspen stem identifies ERF genes that modify stem growth and wood properties. New Phytol. 1239 doi:10.1111/nph.12386

Verica JA, He ZH (2002) The cell wall-associated kinase $(W A K)$ and WAK-like kinase gene family. Plant Physiol 129:455-459

Villalobos D, Diaz-Moreno S, Said E-S, Canas R, Osuna D, Van Kerckhoven SH, Bautista R, 1243 Claros M, Canovas F, Canton F (2012) Reprogramming of gene expression during compres- 1244 sion wood formation in pine: coordinated modulation of S-adenosylmethionine, lignin and 1245 lignan related genes. BMC Plant Biol 12:100

Vinterhalter D, Vinterhalter B, Orbovic V (2012) Photo- and gravitropic bending of potato 1247 plantlets obtained in vitro from single-node explants. J Plant Growth Regul 31:560-569 1248

Wagner TA, Kohorn BD (2001) Wall-associated kinases are expressed throughout plant develop- 1249 ment and are required for cell expansion. Plant Cell 13:303-318 1250

Whetten R, Ying-Hsuan S, Zhang Y, Sederoff R (2001) Functional genomics and cell wall 1251 biosynthesis in loblolly pine. Plant Mol Biol 47:275-291 1252

Wilson BF, Archer RR (1977) Reaction wood: induction and mechanical action. Annu Rev Plant 1253 Physiol 28:23-43

Wilson BF, Chien CT, Zaerr JB (1989) Distribution of endogenous indole-3-acetic acid and 1255 compression wood formation in reoriented branches of Douglas-fir. Plant Physiol 91:338-344 1256

Wyatt SE, Kiss JZ (2013) Plant tropisms: from Darwin to the international space station. Am J Bot 1257 100:1-3

Wyatt SE, Sederoff R, Flaishman MA, Lev-Yadun S (2010) Arabidopsis thaliana as a model for gelatinous fiber formation. Russ J Plant Physiol 57:363-367

Xu W, Purugganan MM, Polisensky DH, Antosiewicz DM, Fry SC, Braam J (1995) Arabidopsis $\mathrm{TCH} 4$, regulated by hormones and the environment, encodes a xyloglucan endotransglycosylase. Plant Cell 7:1555-1567

Yamashita S, Yoshida M, Yamamoto H, Okuyama T (2008) Screening genes that change expression during compression wood formation in Chamaecyparis obtusa. Tree Physiol 28:1331-1340

Yan S, Tang Z, Su W, Sun W (2005) Proteomic analysis of salt-responsive proteins in rice root. Proteomics 5:235-244

Yeh TF, Goldfarb B, Chang HM, Peszlen I, Braun JL, Kadla JF (2005) Comparison of morphological and chemical properties between juvenile wood and compression wood of loblolly pine. Holzforschung 59:669-674

Yeh TF, Morris CR, Goldfarb B, Chang HM, Kadla JF (2006) Utilization of polar metabolite profiling in the comparison of juvenile wood and compression wood in loblolly pine (Pinus taeda). Tree Physiol 26:1497-1503 
1275 Yoshida M, Nakamura T, Yamamoto H, Okuyama T (1999) Negative gravitropism and growth 1276 stress in $\mathrm{GA}_{3}$-treated branches of Prunus spachiana Kitamura f. Spachiana cv. Plenarosea. 1277 J Wood Sci 45:368-372

1278 Yoshinaga A, Kusumoto H, Laurans F, Pilate G, Takabe K (2012) Lignifications in poplar tension 1279 wood lignified cell wall layers. Tree Physiol 32:1129-1136

1280 Yuan S, Wang Y, Dean JFD (2010) ACC oxidase genes expressed in the wood-forming tissues of 1281 loblolly pine (Pinus taeda L.) include a pair of nearly identical paralogs (NIPs). Gene $1282 \quad 453: 24-36$

1283 Zhang XH, Chiang VL (1997) Molecular cloning of 4-coumarate:coenzyme a ligase in loblolly 1284 pine and the roles of this enzyme in the biosynthesis of lignin in compression wood. Plant 1285 Physiol 113:65-74

1286 Zhang Y, Sederoff R, Allona I (2000) Differential expression of genes encoding cell wall proteins 1287 in vascular tissues from vertical and bent loblolly pine trees. Tree Physiol 20:457-466 1288 Zhang Z, Yu J, Li D, Zhang Z, Liu F, Zhou X, Wang T, Ling Y, Su Z (2010) PMRD: plant 1289 microRNA database. Nucleic Acids Res 38:D806-D813

1290 Zhong R, Ye Z-H (2013) Transcriptional regulation of wood formation in tree species. In: Fromm J 1291 (ed) Cellular aspects of wood formation. Springer, Heidelberg, pp 141-158 